\title{
Impact on the Pharyngeal Airway Space after Maxillomandibular Advancement Procedure for Obstructive Sleep Apnea Patients
}

\author{
Ghaddy AlSaty \\ WVU,ga0017@mix.wvu.edu
}

Follow this and additional works at: https://researchrepository.wvu.edu/etd

Part of the Oral and Maxillofacial Surgery Commons, and the Orthodontics and Orthodontology

\section{Commons}

\section{Recommended Citation}

AlSaty, Ghaddy, "Impact on the Pharyngeal Airway Space after Maxillomandibular Advancement Procedure for Obstructive Sleep Apnea Patients" (2019). Graduate Theses, Dissertations, and Problem Reports. 3907.

https://researchrepository.wvu.edu/etd/3907

This Thesis is protected by copyright and/or related rights. It has been brought to you by the The Research Repository @ WVU with permission from the rights-holder(s). You are free to use this Thesis in any way that is permitted by the copyright and related rights legislation that applies to your use. For other uses you must obtain permission from the rights-holder(s) directly, unless additional rights are indicated by a Creative Commons license in the record and/ or on the work itself. This Thesis has been accepted for inclusion in WVU Graduate Theses, Dissertations, and Problem Reports collection by an authorized administrator of The Research Repository @ WVU. For more information, please contact researchrepository@mail.wvu.edu. 
Impact on the Pharyngeal Airway Space after Maxillomandibular Advancement Procedure for Obstructive Sleep Apnea Patients

\title{
Ghaddy AlSaty, D.D.S.
}

\author{
Thesis Submitted \\ To the School of Dentistry \\ at West Virginia University
}

In partial fulfillment to the requirements for the degree of

Master of Science in

Orthodontics

Peter Ngan, D.M.D., Chair

Chris Martin, D.D.S., M.S.

Bryan Weaver, D.D.S., M.D.

Department of Orthodontics

\section{Morgantown, West Virginia \\ 2019}

Keywords: maxillomandibular advancement, sleep apnea, CBCT

Copyright 2019 Ghaddy AlSaty D.D.S 


\title{
ABSTRACT \\ Impact on Pharyngeal Airway Space after Maxillomandibular Advancement Procedure for Obstructive Sleep Apnea Patients
}

\author{
Ghaddy AlSaty, D.D.S.
}

Background and Objectives: Obstructive sleep apnea (OSA) is a sleep-related breathing disorder, characterized by disrupted snoring and repetitive upper airway obstructions. Continuous positive airway pressure (CPAP) is considered the therapeutic mainstay for OSA patients. However, CPAP therapy has compliance limitations. An alternative treatment options is maxillomandibular advancement (MMA) surgical procedure. Genial tubercle advancement (GTA) is often performed concomitant with MMA for esthetic purposes. Cone-beam computed tomography (CBCT) provides the ability to visualize the upper airway and perform three-dimensional (3D) reconstructions. The purpose of this study is to evaluate the impact of MMA procedure with or without GTA on oropharyngeal airway space in OSA patients and the stability after completion of orthodontic treatment.

Methods: A total of 25 patients (18 females and 7 males) with a mean age of $37.1 \pm 17.3$ years were included in the study. CBCT scans were taken before treatment (T1); after pre-surgical orthodontic treatment (T2); immediately after MMA procedure (T3); and at 10 months follow-up visit (T4). Thus, (T2-T1) represented changes due to orthodontic treatment only; (T3-T2) represented changes due to MMA procedure; and (T4-T3) represented changes due to follow-up after surgery. Each patient served as his/her own control. Fifteen of the individuals underwent MMA with GTA. All DICOM files were analyzed using Dolphin 3D Imaging software program to determine total airway volume (TAV), airway area (AA) and minimum axial area (MAA) at explicit regions along the posterior airway space. Dolphin 3D voxel-based superimposition was used to determine the amount of skeletal advancement with MMA and changes after surgery.

Results: Significant increase in TAV, AA and MAA was found with MMA treatment (40.61\%; 28.77\%; and 56.40\%, respectively, $\mathrm{p}<.05)$. Smaller but significant decrease in TAV, AA and MAA was found during the 10 months follow-up visit (20\%; 9.7\%; and 26.8\%, respectively, p<.05). No significant differences were found in airway measurements with or without GTA procedure. No significant differences were found in any of the airway measurements with or without GTA procedure. The average forward movements of the maxilla, mandible and chin were $6.56 \mathrm{~mm}$ and $8.21 \mathrm{~mm}, 11.42 \mathrm{~mm}$, respectively and less than $1 \mathrm{~mm}$ relapse was found during the follow-up period. No correlation was found between the magnitudes of skeletal advancement and the change in oropharyngeal airway space (OPAS).

Conclusions: Significant increase in OPAS can be expected with MMA surgery with or without GTA procedure in patients diagnosed with OSA. Significant forward movement of the maxilla, mandible and chin positions can be obtained with MMA procedure. A partial loss in OPAS was found during the 10 months follow-up period. The surgical movements were found to be stable with less than $1 \mathrm{~mm}$ of relapse during the follow-up period, which was not clinically significant. 


\section{DEDICATIONS}

To my Father, Saud, even though you are not with us anymore, but I am always surrounded by your lovely spirit. Thank you for being the best father and role model for me. And my mother, Sahar, your unconditional love and encouragement kept me going when I was far away from home. I hope that I can be as great parents as the both of you.

To my sisters, Sarah and Mashael, thank you for being there always for me. Thanks for all the fights, laughs and love. I love you both.

To my husband and best friend, Mohamad Sarraj, thank you for being always beside me through our long journey. Your love, patience and upbeat attitude are what kept me afloat when I was overwhelmed with worry. I'm so glad we have the rest of our lives to support each other.

To my son, Bassel, thank you for making me a mother, you have no idea of the amount of joy and happiness you brought into my life. 


\section{ACKOWLEDGEMENTS}

There are a few people without whom this thesis might not have been written, and to whom I am greatly indebted. I would like to take this opportunity to thank not only the individuals who have contributed to my thesis, but also those who have assisted me throughout my specialty training.

Dr. Peter Ngan, for being the chairman of my thesis committee, for your countless hours of dedication to this program, and for your endless commitment to me both personally and professionally. You have been a wonderful mentor, educator, and friend. You have believed in me since the onset of my career and I am truly indebted. I will never ever forget your endless support. Your heart is full of love and support and I thank you.

Dr. Chris Martin, for being a member of my thesis committee, for being a full-time adviser, and for guiding me through my educational journey. I have learned an innumerable amount of knowledge from you, all the while making me laugh on a daily basis. I thank you.

Dr. Bryan Weaver, for being a member of my thesis committee and guiding me throughout this process. I thank you.

Dr. Tim Tremont, thank you for providing an unbelievable foundation for my future orthodontic career. You are a wonderful mentor and educator.

Dr. Mary E. Burns, for your contribution of CBCT scans of subjects utilized throughout this research project and for your continued dedication and drive to produce evidenced based studies. I thank you.

Mrs. June Xiang, for your time and effort in preparing and interpreting the statistical analyses conducted throughout this project. I thank you.

Dr. Manhal Eliliwi, for your time, effort and your invaluable technical assistance conducted throughout this project. I thank you.

Drs. Kerry Kirsch, Tom Jarrett, Lew Wright, Scott Little, Glenn Boyles, Dan Foley, Mike Hazey, Morton Wintner, Erica Reed, Ronnie Sparks and Doyoung Choi for your time and enthusiasm granted to this program. You are great examples of our young orthodontic profession and set a standard in which to aspire. I am thankful that I was given the opportunity to learn from you. Each of you have gifted me a different piece of knowledge in preparing me for the unbelievable journey that I am about to embark. Without hesitation, I thank you.

Karen Pacilli and Marsha Scott, for your support and special assistance offered in clinic. You are an asset and I am so grateful to have gotten the opportunity to work with you. I thank you.

Michele McElory and Carrie Trejo, for your organizational support and assistance with patient scheduling. You are an asset and I am so grateful to have gotten the opportunity to work with you. I thank you.

Niki and Carl - my fellow classmates, for your support you have shown me throughout our time here. Good luck to each of you in your future. 
Marina, Kelly, Dobin, Amer, Mackenzie and Tylor - my former fellow residents, for being great leaders, role models, and teachers. Most importantly, however, were the friendships we developed throughout the course of this residency. The previous two years were quite an experience and you all made it one of the most memorable times of my life. I miss all of you and I thank you.

Sara, Joanna, Dustin, Minh and Stephanie- my fellow residents, Good luck to each of you in your future. 


\section{TABLE OF CONTENTS}

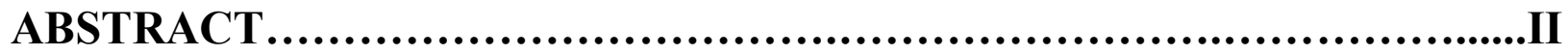

DEDICATIONS...............................................................II

ACKNOWLEDGEMENTS.....................................................IV

TABLE OF CONTENTS..................................................VI

LIST OF TABLES.........................................................

LIST OF FIGURES.....................................................XI

CHAPTER 1: INTRODUCTION.............................................1

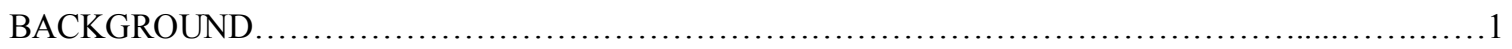

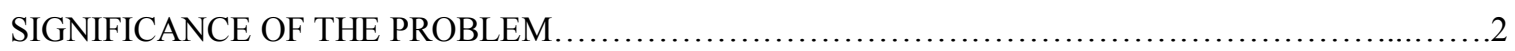

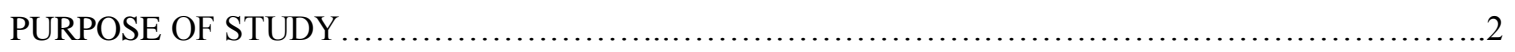

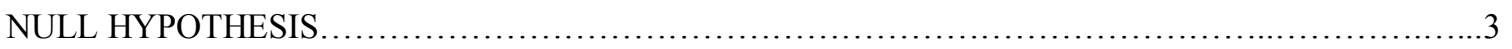

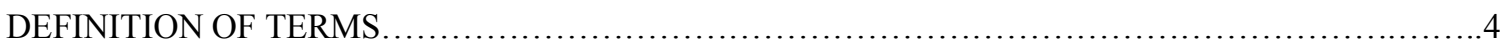

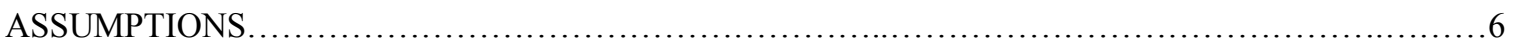

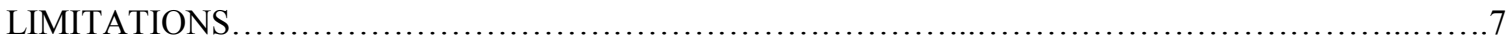

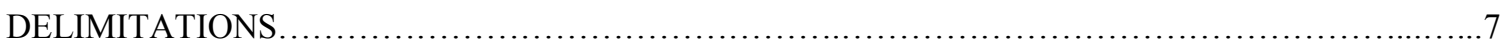

CHAPTER 2: REVIEW OF LITERATURE............................... 8

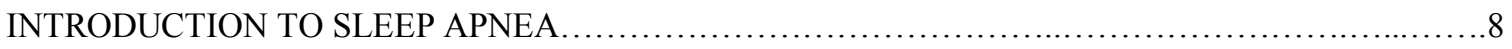

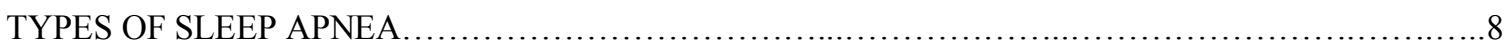




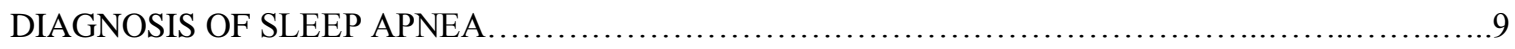

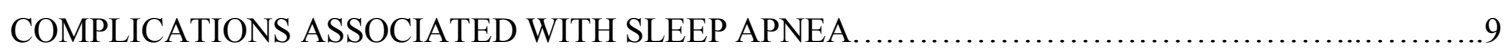

NON-SURGICAL TREATMENT OF SLEEP APNEA ............................................10

SURGICAL TREATMENT FOR SLEEP APNEA..............................................

TRADITIONAL CEPHALOMETRIC AIRWAY ANALYSIS.......................................13

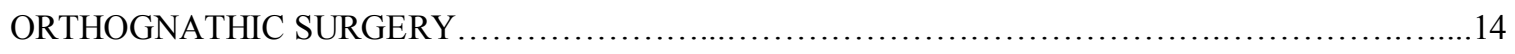

AIRWAY CHANGES WITH MAXILLOMANDIBULAR ADVANCEMENT $\ldots \ldots \ldots \ldots \ldots \ldots \ldots \ldots \ldots . \ldots \ldots$

STABILITY OF MAXILLOMANDIBULAR ADVANCEMENT ................................. 14

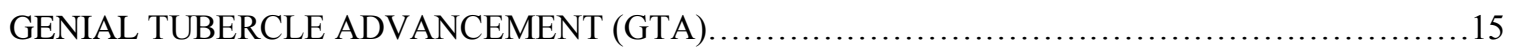

LATERAL CEPHALOMETRIC RADIOGRAPHS............................................ 16

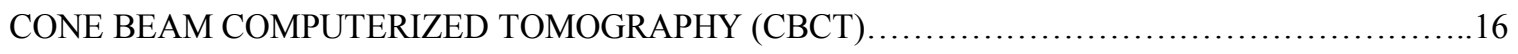

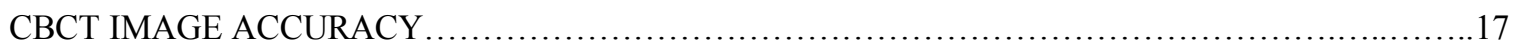

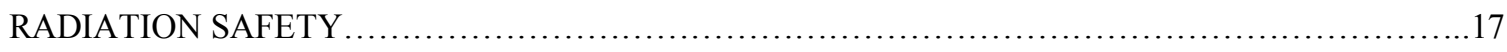

CBCT BENEFITS, APPLICATIONS, AND LIMITATIONS WITHIN ORTHODONTICS................18

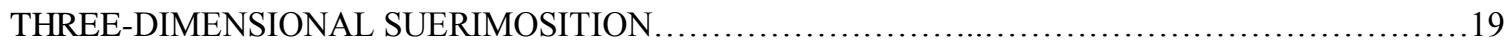

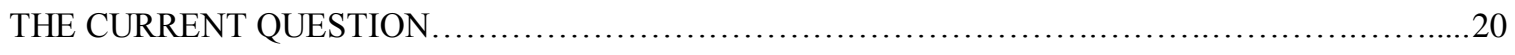

CHAPTER 3: EXPERIMENTAL DESIGN AND METHODS................21

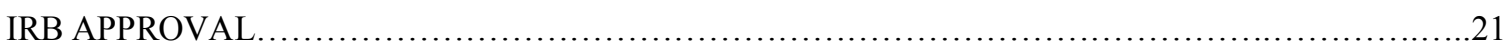

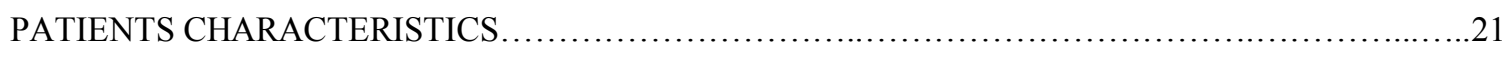

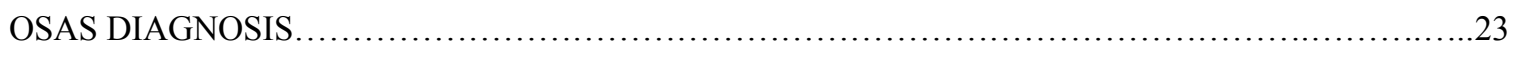

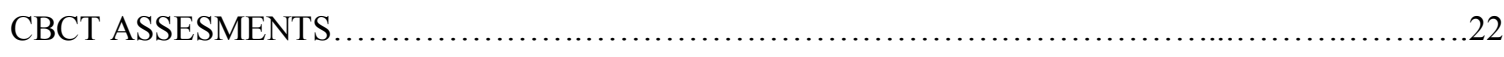


ANALYSIS FOR AIRWAY MEASUREMENTS

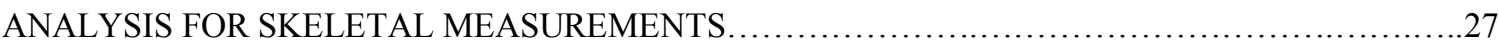

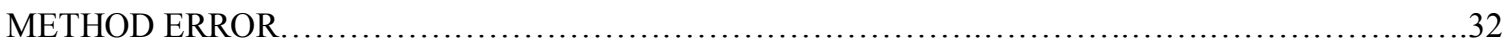

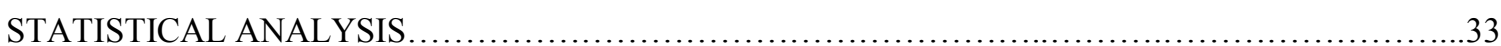

CHAPTER 4: RESULTS...................................................34

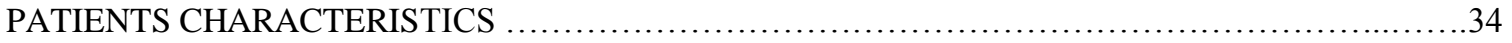

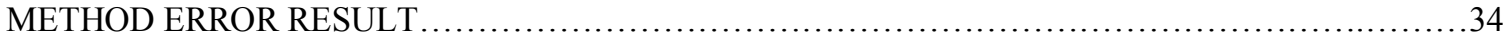

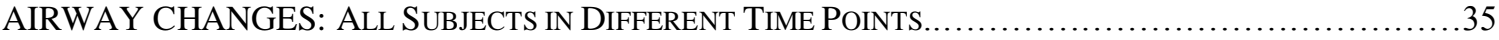

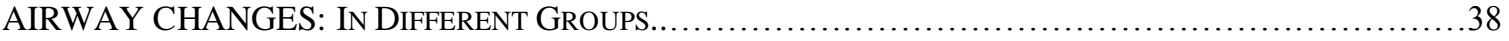

SKELETAL CHANGES: All SubJects In DifFERENT Time PoinTS..................................40

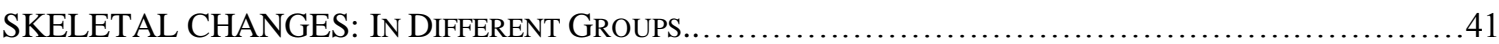

CORRELATION OF AMOUNT OF SKELETAL ADVANCEMENT AND OROPHARYNGEAL AIRWAY MEASUREMENTS

CORRELATION OF SKELETAL RELAPSE AND OROPHARYNGEAL AIRWAY MEASUREMENTS

CHAPTER 5: DISCUSSION.....................................................47

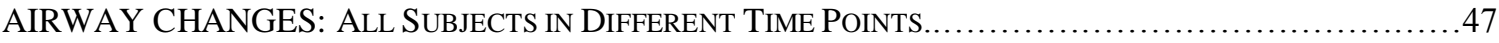

AIRWAY CHANGES WITH SUBGROUPS (AGE, GENDER, GTA PROCEDURE) $\ldots \ldots \ldots \ldots \ldots \ldots \ldots . \ldots 48$

SKELETAL CHANGES: All SubJects in DifFEREnT Time PoinTS.................................48

SKELETAL CHANGES WITH SUBGROUPS (AGE, GENDER, GTA PROCEDURE) .................50

CORRELATION BETWEEN OROPHARYNGEAL AIRWAY MEASUREMENTS AND SURGICAL ADVANCEMENT

.50 
CORRELATION BETWEEN OROPHARYNGEAL AIRWAY MEASUREMENTS AND SURGICAL RELAPSE.

LIMITATIONS OF STUDY .52

CHAPTER 6: SUMMARY AND CONCLUSIONS.............................53 SUMMARY

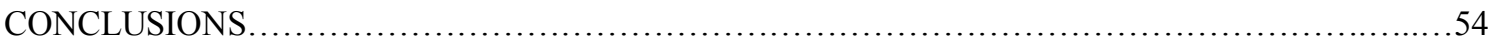

CHAPTER 7: RECOMMENDATIONS FOR FUTURE RESEARCH.........55

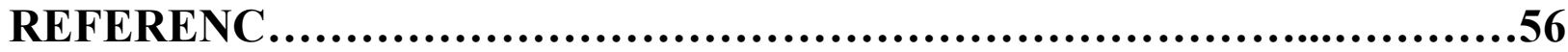

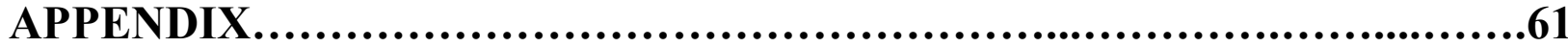

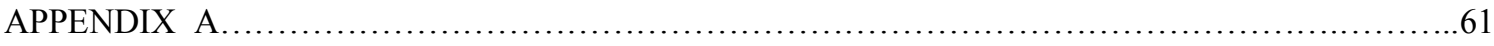

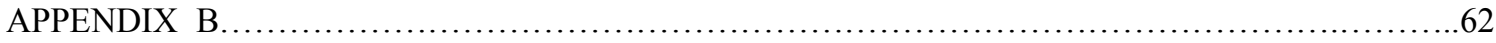

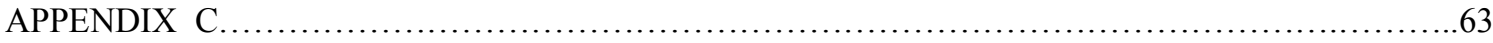




\section{LIST OF TABLES}

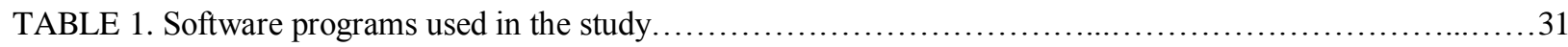

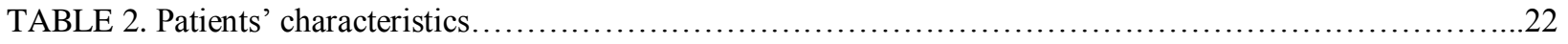

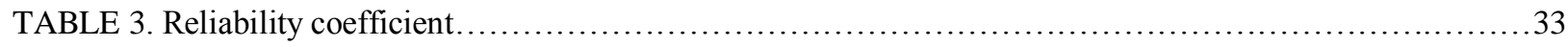

TABLE 4. Changes in airway measurements among different time points.................................35

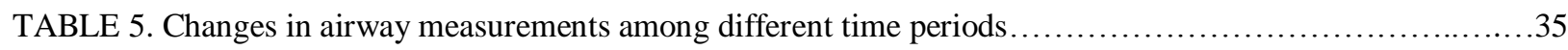

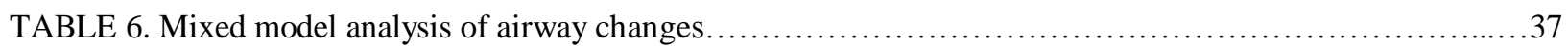

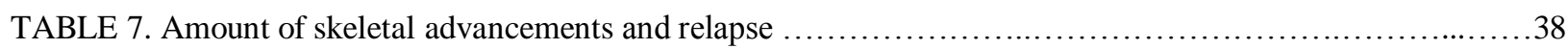

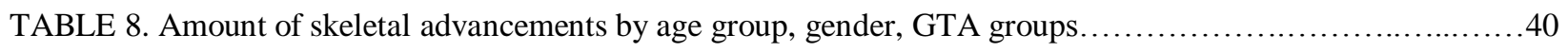

TABLE 9. Amount of skeletal relapse by age group, gender, follow-up, GTA groups..........................41

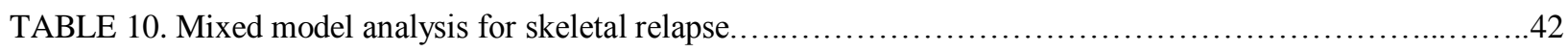

TABLE 11. Pearson correlation test for association between airway measurements at T3 and skeletal advancements

TABLE 12. Spearman correlation test for association between airway measurements at $\mathrm{T} 4$ and skeletal relapse 


\section{LIST OF FIGURES}

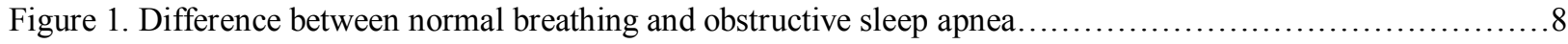

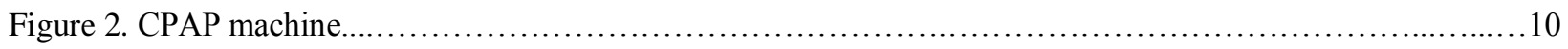

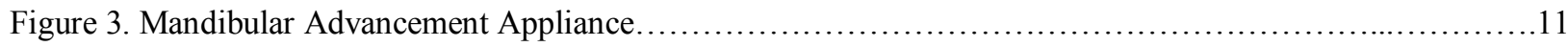

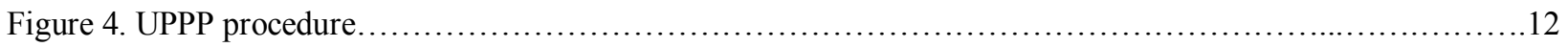

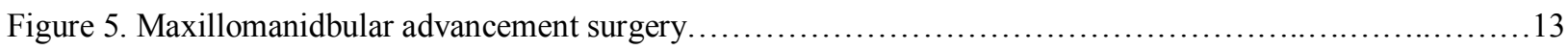

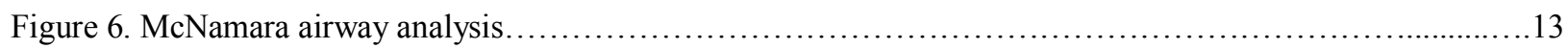

Figure 7. Direction of osseous movement with Genial Tubercle Advancement.................................... 15

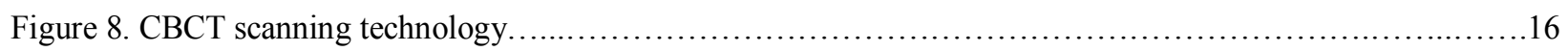

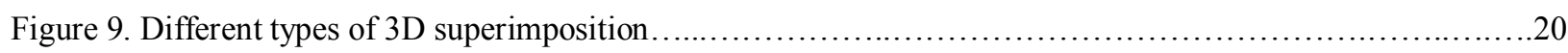

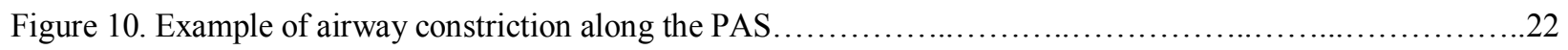

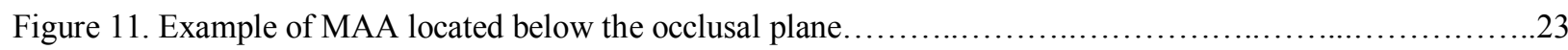

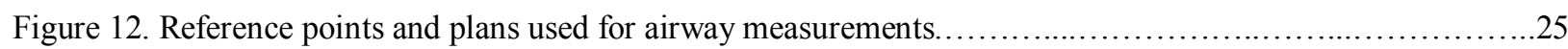

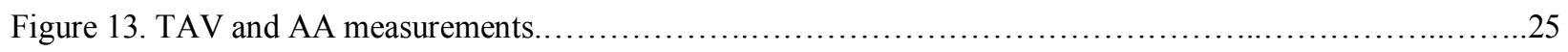

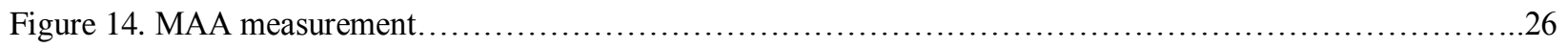

Figure 15. Example of patient's upper pharyngeal airway changes in different time points.......................27

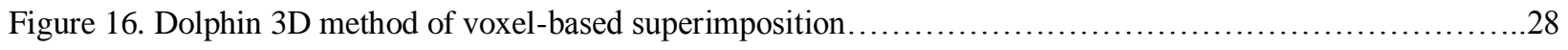

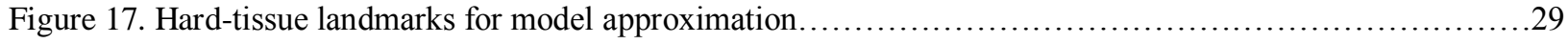

Figure 18. Superimposition of 3D CBCT images with the cranial base structures by using the Dolphin software....29

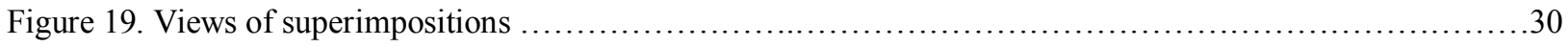

Figure 20. Three-dimensional color map of the registered T3 models showing the differences in millimeters ........31

Figure 21. Fiducial areas were selected using the Pick'n Paint tool in 3D Slicer............................... 31

Figure 22. Example of patient's pre- and post-operative airway and skeletal changes ...........................54 


\section{CHAPTER 1: INTRODUCTION}

\section{Background}

Obstructive sleep apnea syndrome (OSAS) is a sleep-related breathing disorder, characterized by disrupted snoring and repetitive upper airway obstructions. ${ }^{1}$ It results in a continuum of changes in upper airway resistance, reduced blood oxygen levels, fragmentation of sleep, snoring, daytime fatigue, and hypersomnia which often lead to occupational disability and behavioral changes. $^{2}$

Treating patients successfully with OSAS remains a challenge among all dental and medical specialists, and it can be accomplished using both intraoral and extraoral appliances as well as surgery. Continuous positive airway pressure (CPAP) is considered the therapeutic mainstay for OSAS. $^{3}$ Yet a significant minority of patients struggle to adhere to this therapy. ${ }^{4}$ Other treatments for OSAS aimed at enlarging the upper airway while decreasing airway collapsibility include mandibular positioning devices and surgical reduction of the pharyngeal soft tissues. ${ }^{5,6}$ However, CPAP therapy has compliance limitations, and patients still seek alternative treatment options, including upper airway surgery. ${ }^{7}$

Waite et al. first described maxillomandibular advancement (MMA) procedure combined was

first described as a procedure for treatment of patients with OSA. ${ }^{8}$ It was performed by a combination of the Le-Fort I and bilateral sagittal split osteotomies (BSSO) procedures which moved both jaws anteriorly. This leads to anterior repositioning of the soft palate, tongue and pharyngeal tissues. MMA is currently considered to be the most effective craniofacial surgical technique for the treatment of OSAS in adults. ${ }^{9}$ Genial tubercle advancement (GTA) is often performed concomitant with MMA for esthetic purposes. ${ }^{10}$ Body mass index (BMI), age, 
severity of OSAS, airway space, amount of skeletal advancement and relapse of MMA have been reported as clinical factors predictive of surgical success for treatment of patients with OSAS. $^{11}$

Cephalometric imaging has been commonly used to assess the anatomy of the facial skeleton and upper airway. However, it is limited in its representation of 3-dimensional (3D) structures. Cone-beam computed tomography (CBCT) provides the ability to visualize the upper airway and perform three-dimensional reconstructions. It exposes patients to a lower radiation dose than conventional computed tomography (CT), and is a faster procedure. ${ }^{12} \mathrm{CBCT}$ is a noninvasive, effective and reliable technique for airway evaluation. ${ }^{13,14,15} \mathrm{CBCT}$ as well can produce more accurate images without distortion and can be used to evaluate 3D skeletal changes via superimposition with the cranial base structure, which is not affected by surgery. ${ }^{16}$

\section{Significance of Problem}

While CBCT is the preferred method for evaluating pharyngeal airway space (PAS), there has not been extensive research published using this technology when compared to research of PAS utilizing lateral cephalograms ${ }^{17}$. Moreover, there are few follow-up studies evaluating airway and skeletal stability of maxillary and mandibular advancement surgery for OSA patients, even less research is available in the area of 3-dimensional airway and skeletal analysis following

orthognathic surgery ${ }^{18,19,20,21}$ Therefore, more information, from a $3 \mathrm{D}$ perspective is needed to understand the stability of maxillomandibular advancement surgery.

\section{Purpose of Study}


The purpose of this study is to gain a better understanding of the airway changes in OSA patients treated with MMA procedure with or without GTA. In addition, this study determines if there is a relationship between anteroposterior skeletal changes with airway changes and the stability after MMA procedure.

\section{Null Hypothesis}

1. There is no significant difference in oropharyngeal airway measurements (TAV, AA and MMA) between pre-surgical orthodontic treatment (T2-T1) and surgical treatment with MMA procedure (T3-T2).

2. There is no significant difference in oropharyngeal airway measurements (TAV, AA and MMA) between surgical treatment with MMA procedure (T3-T2) and the 10 months follow-up observation (T4-T3).

3. There is no significant difference in oropharyngeal airway measurements for surgery with or without GTA procedure.

4. There is no significant difference in the amount of skeletal advancements (A-Point; BPoint; and Pogonion) with MMA treatment.

5. There is no significant correlation between the amounts of skeletal advancement and the change in oropharyngeal airway measurements with MMA procedure.

6. There is no significant correlation between the amounts of skeletal changes 10 months after MMA procedure with the change in oropharyngeal airway measurements. 


\section{Definition of Terms ${ }^{22}$}

- 2D - Two Dimensional (2-Dimensional)

o Refers to objects that have dimensions of height and width, but do not have depth. Two dimensional objects such as radiographs can be evaluated according to height and width, but do not provide an accurate representation of 3-dimensional structures with have a transverse dimension as well.

- 3D - Three Dimensional (3-Dimensional)

o Refers to objects that have dimensions of height, width and depth. Three dimensional objects better represent actual anatomic structures as long as there is a 1 to 1 ratio.

- Cephalogram

o Synonym for cephalometric radiograph

- Cephalometric Analysis

o A series of measurements based on a radiograph of the head (cephalogram), to determine facial morphology and distinguish dental and skeletal characteristics which are usually compared to norms.

- Cephalometric Radiograph

o A radiograph of the head and neck that is a 2-dimensional representation of these structures.

- Computed tomography (CT) 
o A series of radiographs (flat, two-dimensional grayscale images) that are analyzed and rendered via computer to produce a three-dimensional volumetric or surface mapped image.

- Cone Beam Computed Tomography (CBCT)

o A computed tomography scan utilizing an x-ray beam in the shape of a cone to provide images of bony structures. Data is captured by a flat receiver that detects pulses of cone shaped beam radiation. The result is a stack of two-dimensional grayscale images of the anatomy which can be rendered into volumetric data to visualize anatomical structures in three dimensions. Also known as Cone Beam Volumetric Tomography (CBVT).

- Digital Imaging and Communications in Medicine (DICOM)

o DICOM is a standard for handling, storing, printing, and transmitting medical images. It includes a file format in which data from volumetric radiographs are stored.

- Frankfort Horizontal Plane

o A horizontal plane represented in profile by a line between the lowest point on the margin of the orbit and the highest point on the margin of the auditory meatus.

- Landmark

o A fixed, reproducible (anatomical) point of reference on a radiograph.

- $\quad$ Obstructive Sleep Apnea Syndrome (OSAS)

o A sleep disorder that occurs when a person's breathing is interrupted during sleep. It is caused by a narrowing or blocking of the airway due to the collapse of soft tissues in the 
pharynx and retraction of the genioglossus muscle allowing the tongue to slide further posterior than normal, thus blocking the airway.

- Tomogram

o A radiograph representing a "slice" or sectioned focal area by moving an x-ray source and the film in opposite directions during exposure. Structures in the focal plane appear sharp, while structures in front of and behind the plane are blurred.

- Volumetric

o Visual representation of an image in three dimensional space.

- Voxel

o The smallest element in building a three-dimensional image. It is similar to a "pixel" in a flat two-dimensional image display. Voxel size is important in defining the resolution of a volumetric image (smaller voxel size $=$ higher resolution). The voxel size of a CBCT image can be as small as 0.16 cubic millimeters while the voxel size of a traditional CT image is 0.32 cubic millimeters.

\section{Assumptions}

1. The CBCT scan resolution utilized in this study was adequate to detect skeletal and airway landmarks, without patient movement contributing to the introduction of radiographic artifacts.

2. Landmarks were accurately identified using the CBCT scans.

3. The CBCT scans are 1:1 without the need for calibration. 
4. The operator in this study had working knowledge of the technology utilized in the analysis.

\section{Limitations}

1. The study is limited to the subjects in the database of New Hope Orthodontics, which is the private practice of Dr. Mary E. Burns.

2. There was not enough sleep study reports pre- and post- MMA surgery.

3. There is patient-related variability e.g. medical history, age, gender, BMI, severity of malocclusion and OSA among the subjects.

4. There is treatment-related variability e.g. amount of MMA and GTA procedure.

5. CBCT scans may have artifacts from subject movements, brackets, surgical splints, screws, plates and machine specifications.

\section{Delimitations}

1. The skeletal ages of subjects in the sample have a cervical vertebra maturation stage (CVMS) of 4 or greater.

2. One researcher measures and evaluates all data from CBCT scans.

3. All pre-surgical scans were with the surgical splint in place and taken in centric relation. 


\section{CHAPTER 2: REVIEW OF LITERATURE}

\section{Introduction to Sleep Apnea}

Sleep apnea is characterized by an intermittent cessation or diminution of airflow during sleep that may result in significant pulmonary and cardiac consequences, and is associated with significant morbidity and mortality. It is a common disease that affects approximately $20 \%$ of patients who snore, equating to a total prevalence in the population of about $4 \%$ of all middle aged men and $2 \%$ of women. In reality, due to lack of recognition and the difficulty with obtaining an accurate diagnosis, the actual incidence is likely much higher. ${ }^{23}$ OSA has a multifactorial etiology involving among others a reduced upper airway space, nasal cavity obstruction, distributed body fat mass and muscle tone. ${ }^{24}$

Figure 1. Difference between normal breathing and obstructive sleep apnea. ${ }^{25}$
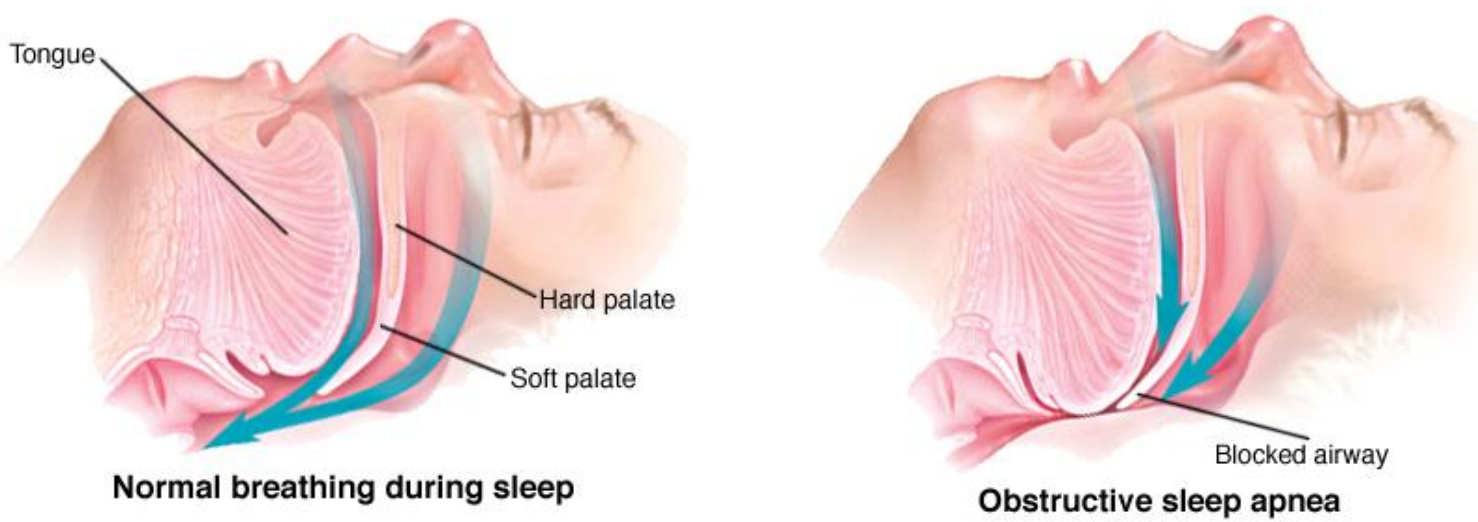

\section{Types of Sleep Apnea}

There are two major forms of sleep apnea: central sleep apnea (CSA) and obstructive sleep apnea (OSA). CSA results from a centrally mediated decrease, or complete lack of, respiratory drive and is manifested by an absence of diaphragmatic and chest wall movement during sleep. Although the etiology of CSA is not well known, it has been associated with a variety of 
neurologic diseases and intracranial lesions such as Arnold-Chiari malformation, as well as a number of medical conditions including gastro-oesophageal reflux disease, obesity and hypothyroidism. Conversely, OSA is associated with normal inspiratory effort against a partially or totally occluded airway. The pathophysiology of OSA is somewhat better understood and is known to be a result of either an anatomical abnormality within the airway leading to occlusion or increased elasticity and compliance of the airway that allows for collapse during inspiration. ${ }^{23}$

\section{Diagnosis of Sleep Apnea}

OSA is diagnosed when there are sleep related clinical symptoms in the presence of at least five obstructive respiratory events per hour of sleep. Alternatively, OSA is diagnosed in the absence of sleep-related clinical symptoms when there are $\geq 15$ obstructive respiratory events per hour of sleep. Obstructive respiratory events during sleep are reported according to the apnea hypopnea index (AHI) or respiratory disturbance index (RDI). Mild OSA is defined as a RDI $\geq 5$ and $<15$ while moderate is defined as a RDI $\geq 15$. OSA is classified as severe when the RDI is $>30 .^{26}$

The AHI is employed to determine the severity of obstructive sleep apnea. It is considered mild when the number of events per hour is between 5 and 20, moderate with 20 to 35 events per hour and severe when the AHI is over 35. An AHI of 5 or under is considered normal in an adult. $^{27}$

\section{Complications Associated with Sleep Apnea}


Individuals with obstructive sleep apnea often experience signs and symptoms that include, but are not limited to: snoring, apneas, morning headaches, fatigue, sleepiness after lunch, memory loss, irritability, poor work performance, altered family relationships, and in some cases alterations in libido. These symptoms may be minimal, where the patient denies sleepiness, or severe, to the point that the subject falls asleep driving and may cause a catastrophic accident. ${ }^{28}$

\section{Non-Surgical Treatment for Sleep Apnea}

Several treatment modalities are available for OSA patients, including weight loss, behavior modification (ie, changing sleep position, decreasing alcohol consumption), and CPAP. ${ }^{29}$ CPAP therapy is first line treatment for patients with OSA. It prevents upper airway collapse, relieves symptoms such daytime sleepiness and decreases cardiovascular events. However, for various reasons this treatment has poor compliance. ${ }^{30}$

Figure 2. CPAP machine. ${ }^{31}$

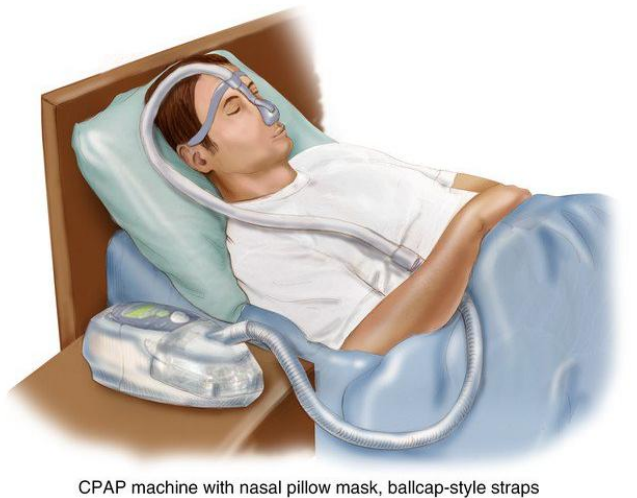

CPAP machine with nasal pillow mask, ballcap-style straps

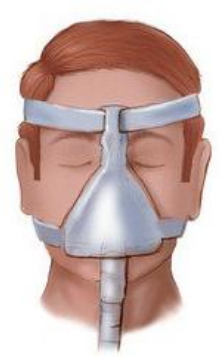

Full face mask, side straps

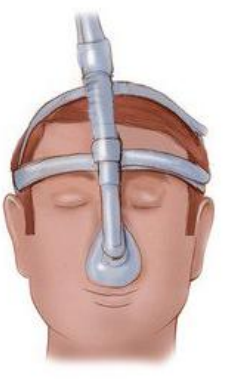

Nasal pillow mask, ballcap-style straps

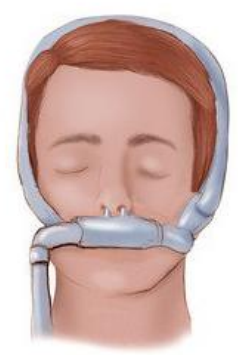

Nasal pillow mask, side straps

Oral appliance therapy is an effective alternative and is especially effective in mild-to moderate OSA cases. Most oral appliances used in a clinical setting are mandibular advancement devices (MADs), which keep the mandible and its attached musculature in a protruded position. 
Successful oral appliance therapy has been suggested as a predictor for successful MMA surgery in OSA patients. ${ }^{32}$

Figure 3. Mandibular Advancement appliance. ${ }^{33}$

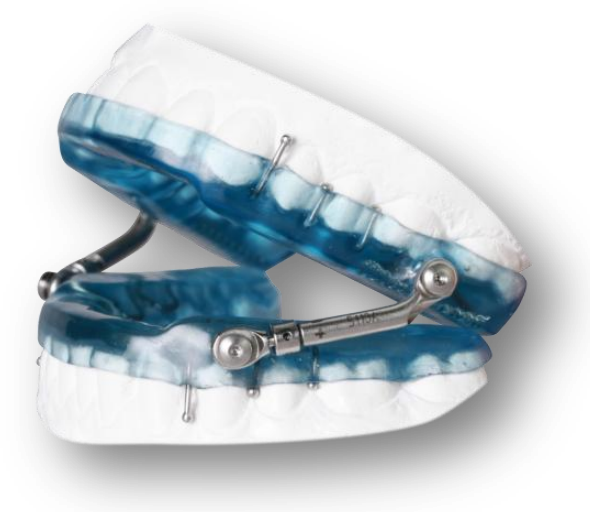

\section{Surgical Treatment for Sleep Apnea}

Patients who have failed conservative therapy, are noncompliant with their CPAP appliances, or present with AHI $>50$, oxygen desaturations $<85 \%$, morbid obesity, or failure to respond to other modalities of treatment generally will require surgical intervention for cure. ${ }^{32}$ The surgical protocol includes a pre-surgical evaluation to isolate areas of obstruction; this evaluation is followed by potentially 2 phases of surgery. Phase I surgical treatment is based on the level of obstruction, as determined in the pre-surgical evaluation. Surgical treatment can include Uvulopalatopharyngoplasty (UPPP) for oropharyngeal obstruction and/or genioglossus advancement with hyoid suspension (GAHM) for base-of-tongue obstruction. Successful clinical outcomes of phase I surgery are based on severity and range from approximately $75 \%$ in patients with mild-to-moderate OSA to $40 \%$ in patients with severe OSA. Outcomes are reported on a 6month postoperative polysomnogram. ${ }^{34}$ 
In the case of a retropalatal obstruction, UPPP has been widely used and remains a common treatment option in some centres. This surgical procedure was first described by IKEMATSU in 1964, exclusively as a treatment to abolish the noise of snoring. In 1981, FUJITA described UPPP as a means of treating OSA. Since then, the operative technique of UPPP has been modified several times but, despite such modifications, UPPP often only led to a reduction in snoring, while the pharyngeal obstruction and the resulting sleep fragmentation of OSA remained. Furthermore, many long-term studies of UPPP treatment for OSA have shown a fall in success rates with the passage of time. ${ }^{35}$

Figure 4. UPPP procedure. ${ }^{36}$
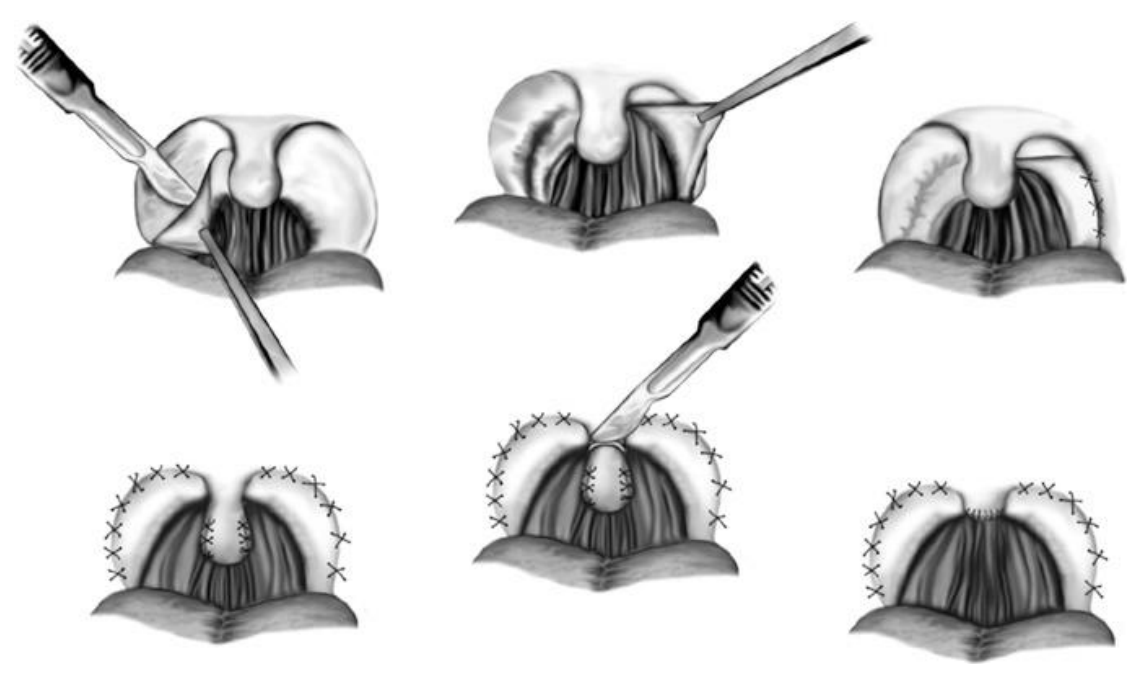

Phase II surgical reconstruction is reserved for phase I failures and consists of maxillary and mandibular advancement osteotomy. Severe OSA presents many difficult challenges; however, surgical success at 6 months is approximately $95 \%$, which is the same as the effectiveness rate of nasal CPAP. ${ }^{34}$ 
Figure 5. Maxillomanidbular advancement surgery. ${ }^{37}$
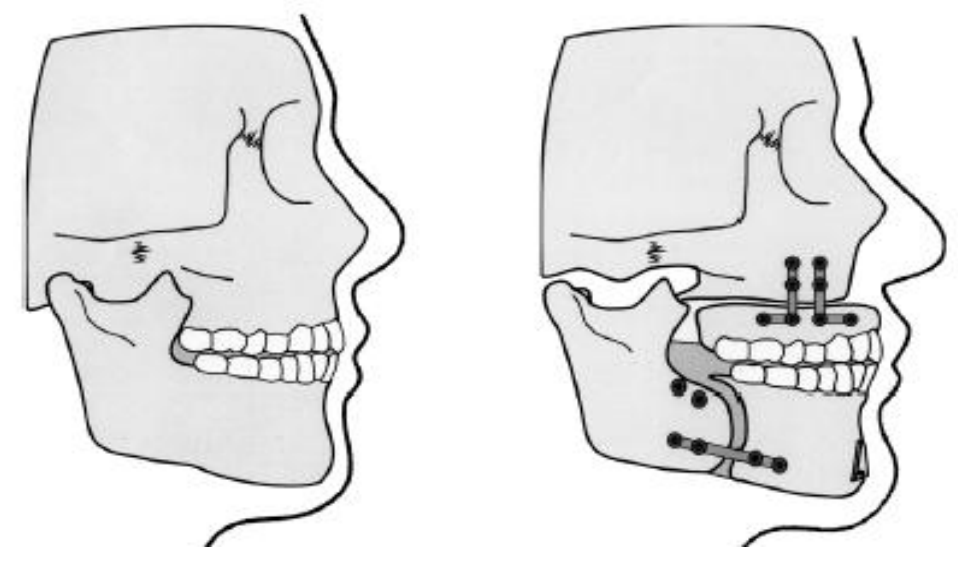

\section{Traditional Cephalometric Airway Analysis}

The most widely used orthodontic airway analysis was derived by McNamara in 1984. This analysis consists of measuring the airway using a 2D cephalometric image. The McNamara analysis utilizes only two measurements taken from a lateral cephalogram to examine the possible airway dysfunction ${ }^{38}$. However, these values only give information on 2 sites where as airway obstruction can occur at multiple sites and therefore this analysis is not useful in diagnosing OSA in adults.

Figure 6. McNamara airway analysis. ${ }^{39}$

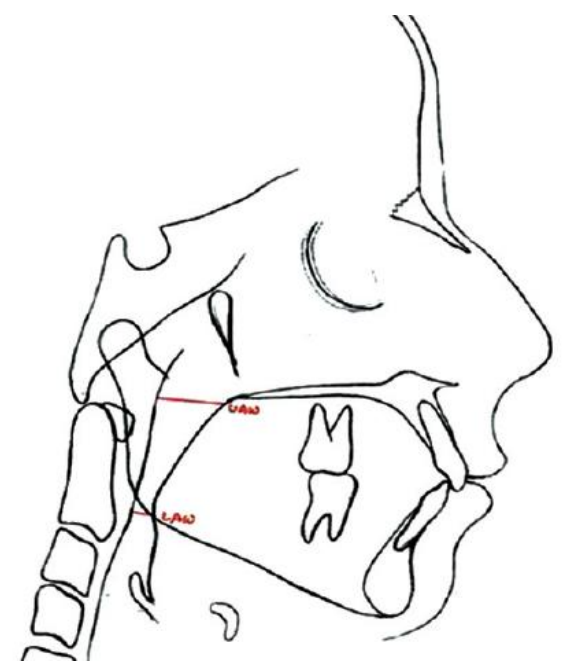




\section{Orthognathic Surgery}

Orthognathic surgery is used to treat a variety of facial and jaws abnormalities in which the upper and lower jaws and the teeth are not in an acceptable relationship. Patients generally experience both functional and psychosocial benefits after undergoing orthognathic treatment. ${ }^{40}$

\section{Airway Changes with Maxillomandibular Advancement}

Maxillomandibular advancement surgery, often in conjunction with genial tubercle advancement, has been shown to be an effective surgical alternative for the treatment of OSA . Despite the fact that there is no direct manipulation of pharyngeal tissue, MMA is believed to improve OSA because the skeletal movements favorably alter upper airway shape. ${ }^{41}$ It enlarges the entire posterior airway and increases the tension on the suprahyoid and airway musculatures by elevating the tissues and musculatures attached to the maxilla, mandible and hyoid. However, even at slightly less advancement, postoperative CBCT examination revealed that the oropharyngeal volume was doubled in size, and the surface area of minimal axial slice was more than tripled in size compared with the pretreatment records. ${ }^{23}$ It seems the influence of mandibular advancement on the pharyngeal airway volume is greater than the effect of the forward movement of the maxilla. ${ }^{13}$

\section{Stability of Maxillomandibular Advancement}

Evaluation of skeletal stability of MMA is important because the amount of skeletal advancement (and therefore its stability) has been considered to be a significant predictor of success in the surgical treatment of OSA. ${ }^{41}$ The effectiveness of MMA for the treatment of OSA 
has been confirmed in short and long term follow-up studies employing both objective (polysomnograms) and subjective data (patient questionnaires). Advancement of the maxillomandibular complex $10 \mathrm{~mm}$ for treatment OSA remains stable at a mean follow up period greater than 2 years and preoperative orthodontic treatment does not appear to influence skeletal stability. ${ }^{41}$

\section{Genial tubercle advancement (GTA)}

Genial tubercle advancement was first described by Riley et al in 1984. GTA pulls the geniohyoid and genioglossus muscles forward. MMA in conjunction with GTA leads to the anterior movement of the soft palate, base of the tongue, hyoid bone, and anterior pharyngeal tissues, resulting in an increase in volume of the nasopharynx, oropharynx, and hypopharynx and therefore increasing the posterior airway space. Because of the increase in posterior airway space, surgical success for treatment of OSA is obtained with significant improvement of the patient's symptoms and a decrease of pathologic sleep events. ${ }^{29}$

Figure 7. Direction of osseous movement with Genial Tubercle Advancement. ${ }^{36}$

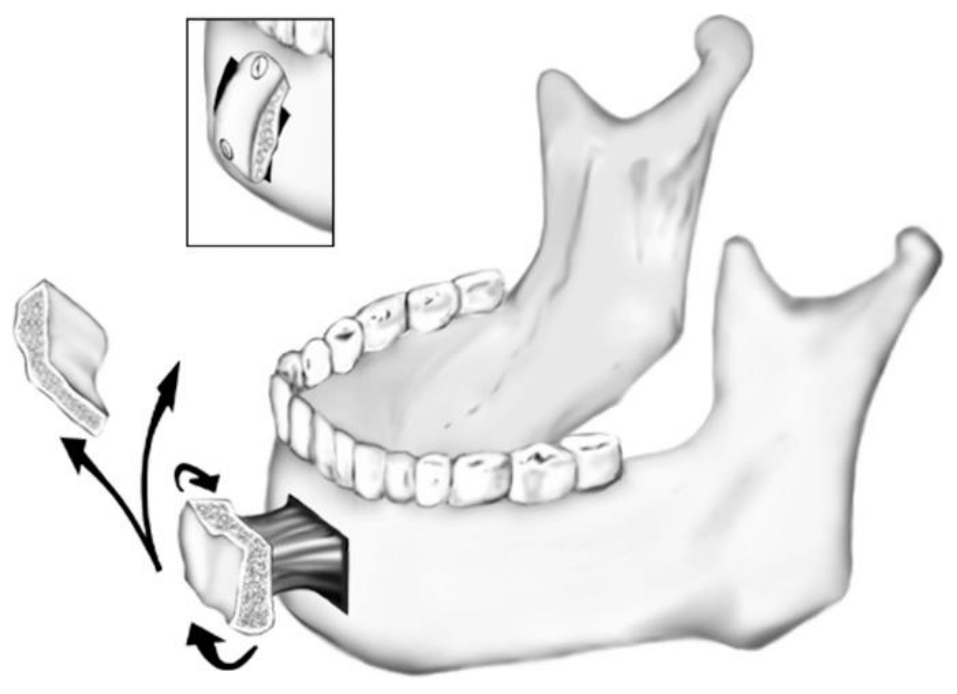




\section{Lateral Cephalometric Radiographs}

Most studies were based on lateral cephalometric radiographs because such radiographs are part of the records used for proper planning of orthodontic treatment. Although it can provide a wealth of information, cephalometric radiography is limited in the sense that it produces twodimensional images (height and depth) of a three-dimensional structure, therefore hindering accurate assessment of the size and complexity of this structure. ${ }^{24}$

\section{Cone Beam Computerized Tomography (CBCT)}

CBCT scanners have been available for craniofacial imaging since 2001 in the United Sates. Their compact size and relatively low radiation dosage make the CBCT scan an imaging modality that helps address the previously stated challenges effectively and efficiently. ${ }^{42}$

$\mathrm{CBCT}$ has made it possible to acquire 3D image volumes of all structures in the maxillofacial complex. With the use of specific software and acquisition protocols based on individual needs, these digital volumetric scans can be turned into multiple planar view images (axial, coronal and sagittal). Software tools also allow bone structure measurements to be obtained as well as 3D assessment of soft tissues, and the shapes, volumes and features of the face and upper airways. ${ }^{24}$ Figure 8. CBCT scanning technology. ${ }^{43}$

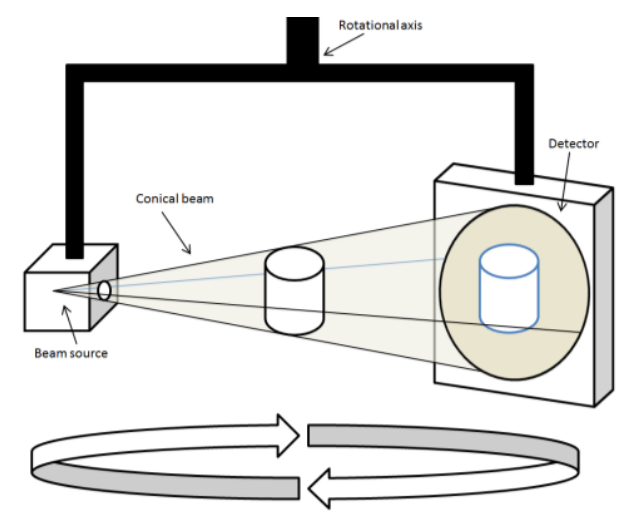




\section{CBCT Image Accuracy}

CBCT scans allow the orthodontist to assess the patient's hard and soft tissue in three dimensions. The accuracy and reliability of such images have been tested and were found to be adequate for implant planning, periodontal disease quantification, and assessment of tumor/lesion volumes. Today, existing software allows us to take full advantage of CT scans in performing 3D measurements and developing 3D craniofacial analyses. These 3D measurements, made on CT images, can be more accurate and reproducible and have the potential to aid in the craniofacial diagnosis of facial asymmetries, functional shifts, and canted occlusal planes. CBCT craniometric measurements are accurate to a subvoxel size and potentially can be used as a quantitative orthodontic diagnostic tool. ${ }^{44}$ Presence of soft tissue as well as different voxel size affect the precision of the data. A customized resolution protocol must be chosen according to the accuracy needed. ${ }^{45}$ When CBCT is taken, the accuracy and reliability of craniofacial measurements is shown to be better, compared to $2 \mathrm{D}$ cephalogram. ${ }^{46}$

\section{Radiation Safety}

Various reports have described the radiation exposure associated with CBCT scans. Only a $20 \%$ reduction in the total radiation dose associated with CBCT compared with conventional CT. However, 3D volumetric images obtained with cone beam technology involved up to four times less radiation than conventional $\mathrm{CT}$. Settings such as peak kilovoltage $(\mathrm{kVp})$ and milliampere $(\mathrm{mA})$ are some of the factors which affect the effective radiation dose. The use of lower mAs and/or collimation can reduce the amount of radiation the patient receives, although these settings can also reduce image quality. The effective exposure dose for a patient from a CBCT machine has been reported to range from 45 microsievert $(\mu \mathrm{Sv})$ to $650 \mu \mathrm{Sv}$. The reported doses 
for an analog full mouth series and an analog panoramic radiograph are $150 \mu \mathrm{Sv}$ and $54 \mu \mathrm{Sv}$, respectively. ${ }^{47}$ Radiation dose from CBCT scans is significantly less than other computed tomographic imaging methods such as medical computed tomography and is within the range of traditional dental imaging methods. ${ }^{28}$

\section{CBCT Benefits, Applications, and Limitations within Orthodontics}

Three-dimensional CBCT images provide additional diagnostic information on (1) size, shape, and position of mandibular condyle heads; (2) width of the tooth-bearing portion; (3) morphology, inclination, displacement, or deviation of the lateral and medial surfaces of the mandibular rami and body; (4) dental root positioning; (5) localization of impacted or supernumerary teeth; (6) palatal morphology; and (7) morphology of sites for placing implants or osteotomies. This information can help in identification of affected structures, treatment planning, and future comparisons with long-term follow-up of treatment stability. The identification of the soft-tissue profile allows assessment of hard and soft tissue relationships. ${ }^{48}$ CBCT technology allows the segmentation and visualization of hollow structures such as the airway in 3 dimensions. Thus, with 3D imaging, we are moving from lengths and angles toward volumes and surface areas. $^{49}$

However, CBCT does not assess muscular morphology, and magnetic resonance imaging allows still more accurate renderings of the soft tissues. ${ }^{48}$ Besides the anatomy of the skeletal and soft tissue, airway space depends on some dynamic variables such as lung volume, intraluminal and extraluminal pressure, muscle tone and head position. Since the soft palate and the tongue are structures composed of soft tissue with no rigid support, they are greatly affected by gravitational forces. Therefore, in CT scans and other examinations performed in the supine 
position, these structures move further toward the posterior pharyngeal wall, which results in changes in the dimensional measurements of the upper airway space. Thus, scan results obtained with the patient sitting cannot be extrapolated or even directly compared to those obtained with the individual in the supine position. The latter position is recommended for individuals with OSA. Lohse et al suggest that in assessing OSA patients a modification be made to the CBCT acquisition technique, namely, removing the chin positioner so that the patient can hold their head in a natural position. Airway space size and morphology vary when the patient inhales or exhales. CT scan acquisition time is around 20-40 seconds, too long for the individual to control their respiratory movements. Hopefully, in the near future CBCT acquisition time will be faster in order to prevent patient movements (breathing, swallowing and involuntary movements) from interfering with the results. ${ }^{24}$

\section{Three-Dimensional Superimposition}

The use of CBCT images in clinical orthodontics calls for a fast and accurate way to superimpose these images to evaluate craniofacial growth or treatment changes. Currently, there are three ways of superimposing 3D images: landmark based, surface based, and voxel-based. Landmark superimposition is similar to 2D superimpositions, using anatomic landmarks or lines as references. Landmark identification on $3 \mathrm{D}$ images is much more complex than on $2 \mathrm{D}$ cephalometric radiographs since landmark locations in 2D radiographs are usually easier to identify because of the nature of the images. Surface-based superimposition deals with the shell covering the 3D structure and requires high quality surface models for an accurate superimposition. Voxel-based superimposition matches the grayscale values of the voxels (density) to superimpose the CBCT images. Voxel-based superimposition is fully automated and 
uses the radiopacities and radioluscencies throughout the selected volume, removing the chance of operator error, which is the main disadvantage of the landmark superimposition method. Dolphin 3-dimensional voxel-based superimposition, a fast and user-friendly method, is precise and reliable. ${ }^{14}$

Surface-based and voxel-based superimposition methods using the anterior cranial base as a reference structure were accurate and reliable in detecting changes in landmark positions when superimposing. Landmark-based superimposition method was reliable but less accurate than the other methods. ${ }^{50}$

Figure 9. Different types of 3D superimposition. A. landmark based; B. surface based; C. voxel-based. $^{50}$
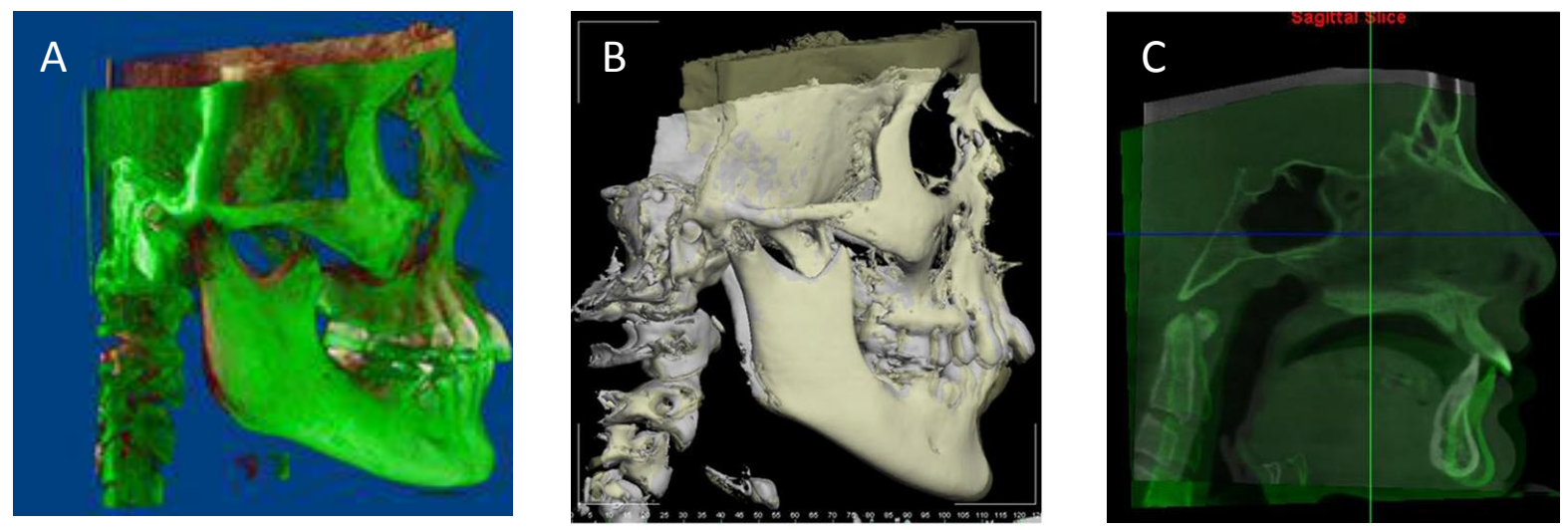

\section{The Current Question}

There is clear evidence that MMA surgery improves airway patency in patients with sleep apnea. ${ }^{27}$ However, much of this research was conducted using a 2-dimensional cephalograms and without long-term follow-up observation. This study determines the short- and long-term airway and skeletal changes after MMA surgery with or without GTA via CBCT. 


\section{CHAPTER 3: EXPERIMENTAL DESIGN AND METHODS}

\section{IRB Approval}

Protocol \#1704532922 was reviewed and exempted by the Institutional Review board at West

Virginia University (See Appendix A). Permission to use patient data was obtained from one of the investigators Dr. Mary E. Burns (See Appendix B).

\section{Sample Descriptions}

This retrospective cohort study included 25 patients with an average age of 37.1 years (range, 15-62 years) who were diagnosed with OSAS.

The inclusion criteria were as follows:

- Patients who were treated with MMA procedure with or without GTA

- Patients who were 15 years or older

- Patients who were diagnosed with OSAS with polysomnography or airway constriction at one or more levels along the posterior airway space

- Patients who had moderate to severe OSAS for which they could not tolerate CPAP therapy

- Patients with adequate radiographic documentation.

The exclusion criteria were as follows:

- Patients with previous history of orthognathic or maxillofacial surgery.

- Patients with craniofacial abnormalities.

\section{Patients' Characteristics}


This study is in collaboration with Dr. Mary E. Burns, clinical orthodontist, in New Hope, Pennsylvania. A total of 35 patients were collected but only 25 patients were selected due to adequate radiographic records. The sample consists of 25 Caucasians patients (18 females and 7 males) with a mean age of $37.1 \pm 17.3$ years who were evaluated for OSA and underwent MMA surgical treatment between 2011 and 2016. Fifteen (10 females and 5 males) of these patients specifically underwent MMA with GTA.

\section{OSAS Diagnosis}

Patients who were diagnosed with OSAS with polysomnography or airway constriction at one or more levels along the posterior airway space were included in this study. According to Ogawa et al. $^{9}$ the location of the smallest cross-sectional area in patients with OSA was below the occlusal plane in greater than $70 \%$ of the subjects. The current study found that the majority of the patients had their minimum axial area located below the occlusal plane. Another study has shown a statistically significant relationship between the narrowest cross section of the upper airway and the probability of OSA. A small airway area of about 40 to $67 \mathrm{~mm}^{2}$ is associated with OSA. $^{51}$ In the current study we found that some patients have this criterion as well. This indicates that although not all patients were clinically diagnosed with OSA, they will likely benefit from MMA.

Figure 10. Example of airway constriction along the PAS. 


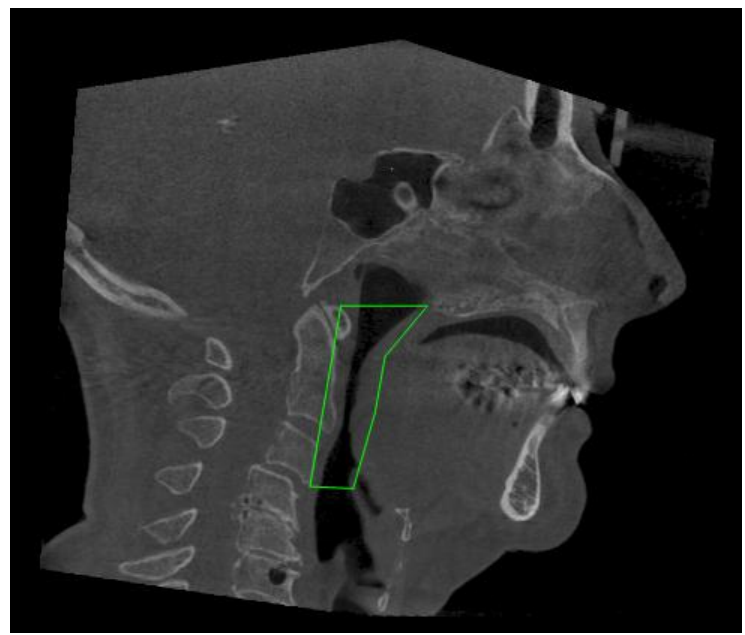

Figure 11. Example of MAA located below the occlusal plane.

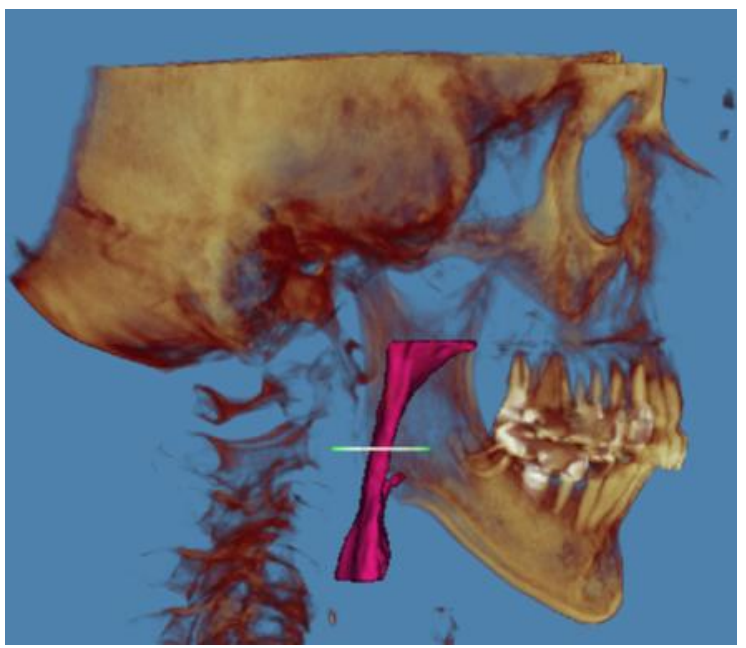

\section{CBCT Assessments:}

\section{- Imaging Protocol}

The DICOM files of the subjects participated in the study were de-identified and coded by numbers. The volumetric images were obtained with Kodak 9500 CBCT unit. All images were calibrated using the same following parameters: exposure of $10 \mathrm{~mA}$ for 10.8 seconds, power of $90 \mathrm{kVp}$ and full field of view. Each scan contained 598 slices sufficiently encompassing the region of interest.

\section{- Image Acquisition}


The CBCT scans were taken before treatment (T1); after pre-surgical orthodontic treatment (T2); immediately after MMA procedure (T3); and 10 months follow-up visit (T4). Thus, (T2-T1) represented changes due to orthodontic treatment only; (T3-T2) represented changes due to MMA procedure; and (T4-T3) represented changes due to follow-up after surgery. Each patient served as his/her own control. During image acquisition, the patient was in a natural head posture and in a maximum interception position.

\section{Analysis for Airway Measurements}

For airway analysis, Dolphin (version 11.95, Dolphin Imaging \& Management Solutions, Chatsworth, Calif.) imaging software was used to assess the total airway volume (TAV), airway area (AA) and the minimal axial area (MAA) selected from these predefined structures.

The sites for the posterior airway space assessment were chosen as the landmarks were easily and reproducibly identified on 3D images. Utilization of these references and landmarks allowed for standardized data collection, thus minimizing the chances of invalid calculations.

The following reference points were used to analyze the airway measurements:

- ANS: The most anterior point on the hard palate.

- PNS: The most posterior point of the hard palate.

- CV3: The most anterior inferior point of the body of the third cervical vertebra.

The following reference planes were used to analyze the airway measurements:

- Palatal Plane: A horizontal plane passing through ANS and PNS extending to the posterior wall of the pharynx. 
- CV3 Plane: A plane parallel to the palatal plane passing through CV3 and the base of epiglottis.

Figure 12. Reference points and plans used for airway measurements.

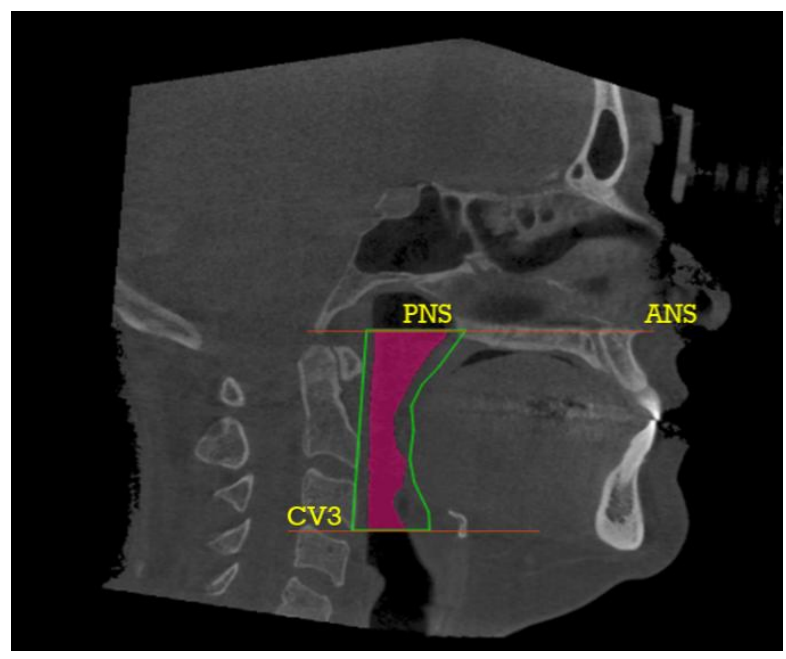

Boundaries to measure total airway volume were as follows:

- Anterior: A vertical plane through PNS, the soft palate, the base of the tongue, and the anterior wall of the pharynx.

- Posterior: The posterior wall of the pharynx.

- Lateral: The lateral walls of the pharynx.

- Superior: A horizontal plane passing through ANS and PNS.

- Inferior: A horizontal plane passing through CV3.

TAV and AA measurements of the airway were then calculated by using axial slices through ANS, PNS, and CV3 for each patient in all time points.

Figure 13. TAV and AA measurements. 

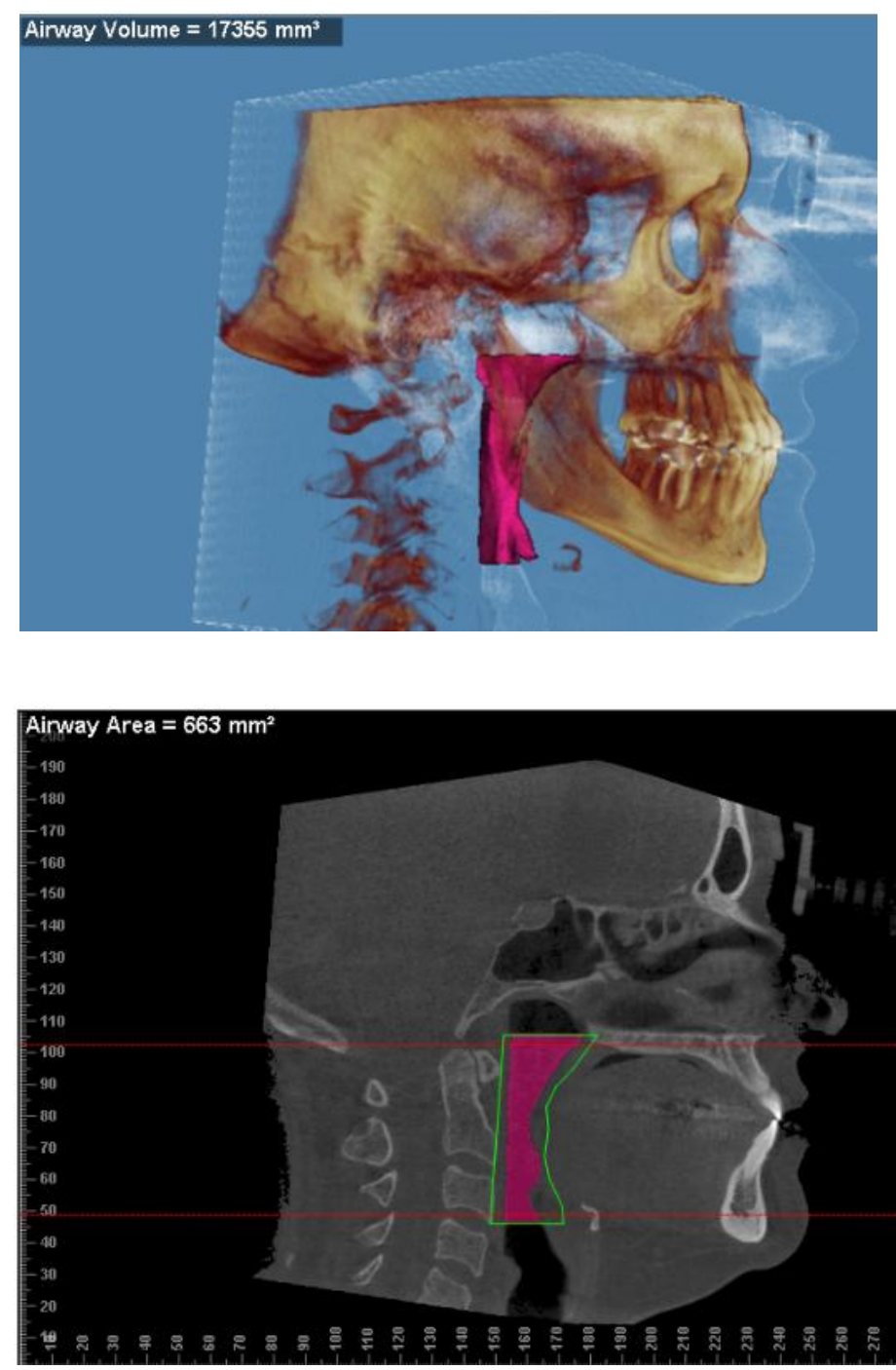

After cross-sectional measurements were taken, the MAA was also found for each patient in all time points. The minimal axial area was calculated by using a specific analysis tool in Dolphin.

Figure 14. MAA measurement. 


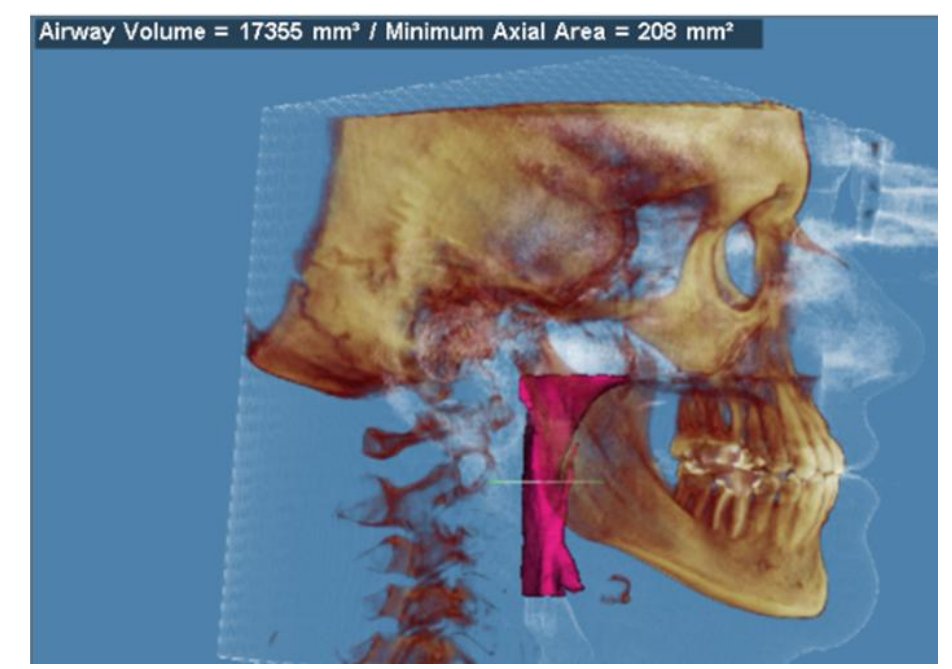

Figure 15. Example of patient's upper pharyngeal airway changes in different time points. A. T1; B. T2; C. T3; D. T4.
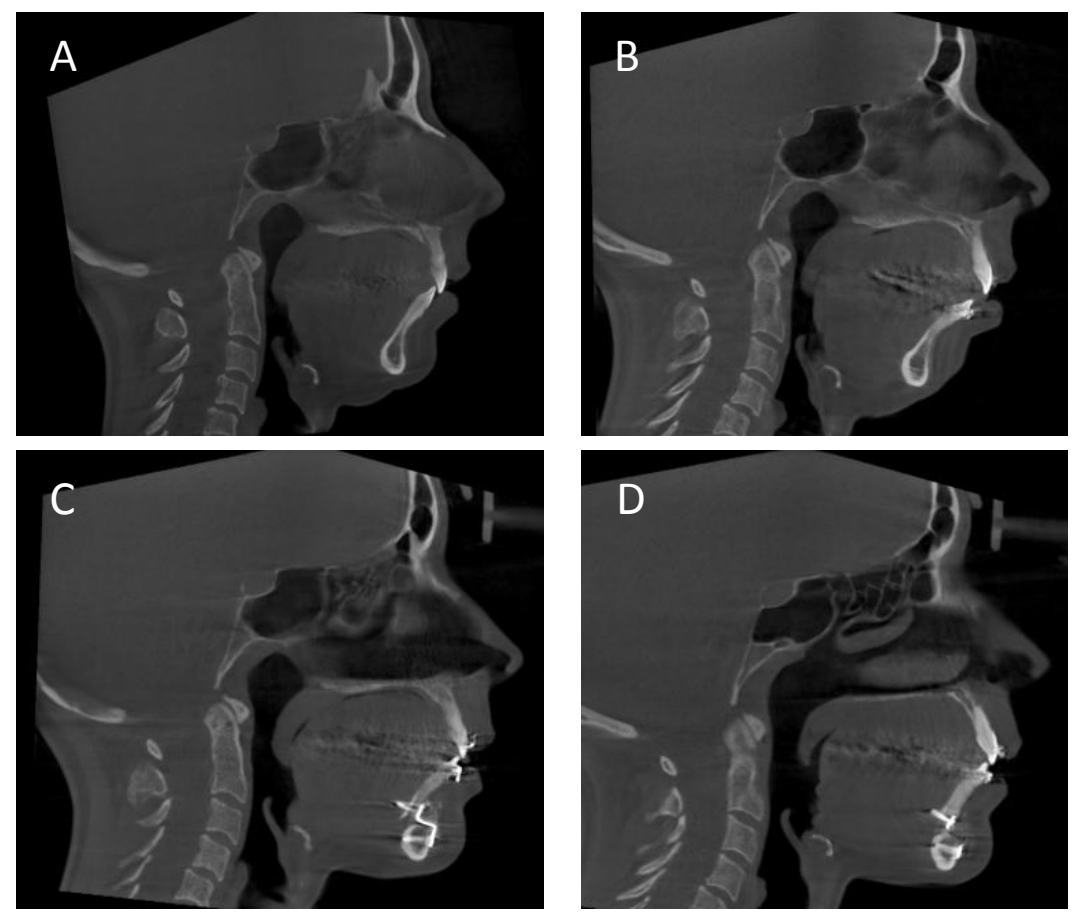

\section{Analysis for Skeletal Measurements}

For skeletal measurements, Image analysis was done by using Dolphin 3D method of voxelbased superimposition ${ }^{48}$ (See Fig. 12) in five steps: image approximation, image superimposition and registration, image segmentation, model construction and quantitative measurement. 
Dolphin, ITK-SNAP (version 3.2; http://www.itksnap.org) and 3D Slicer (version 4.8; http://www.slicer.com) imaging software programs were used (See Table 1) to assess the skeletal changes and relapse after MMA.

Figure 16. Dolphin 3D method of voxel-based superimposition. ${ }^{48}$

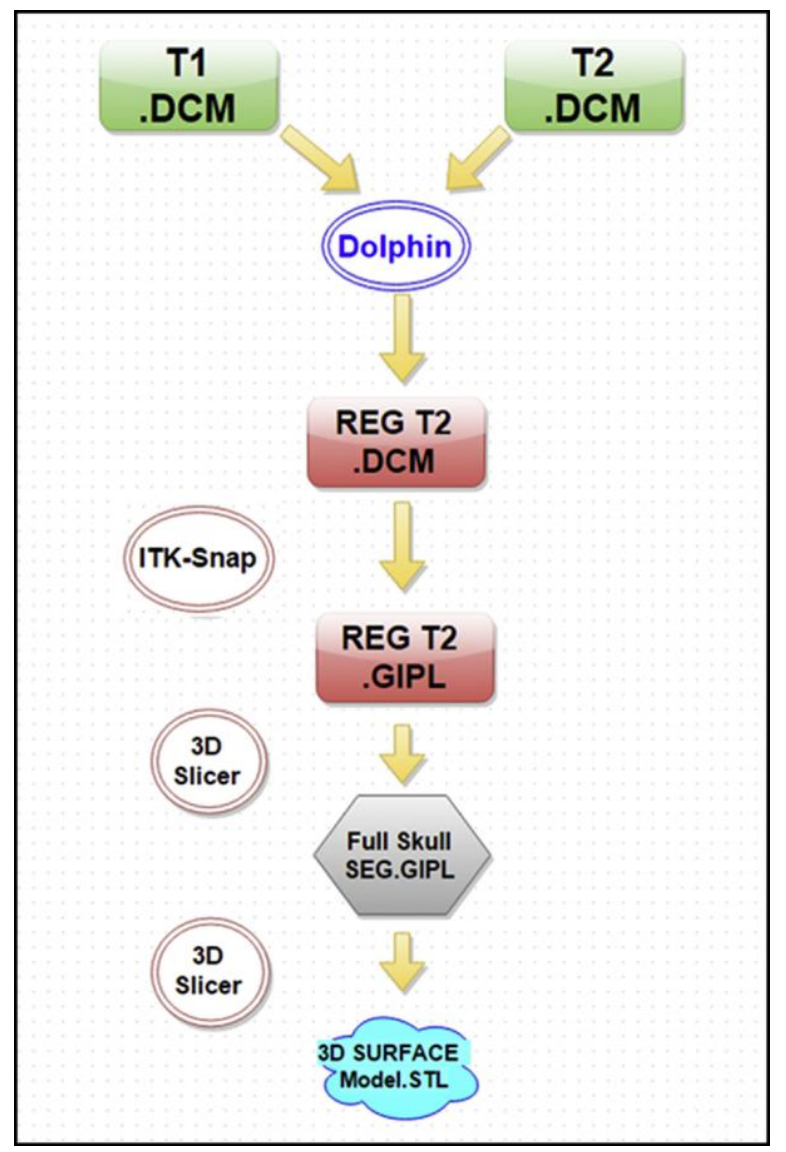

\section{3D Image Approximation}

Each data set was imported directly into Dolphin. T2 and T3 3D images were approximated using four landmarks unaffected by the surgery located at the right and left of the frontozygomatic sutures and the right and left of the inner curvature of zygomatic arch. After selecting these regions, the automatic affine registration tool of Dolphin was used for model approximation. 
Figure 17. Hard-tissue landmarks for model approximation. A. T2; B. T3.
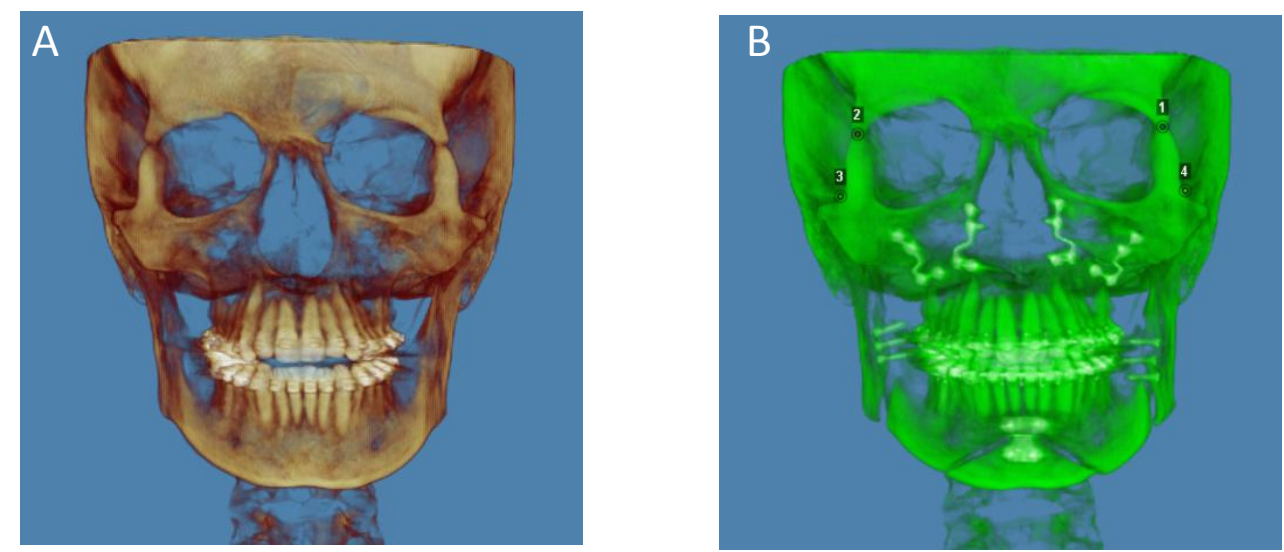

\section{3D Image Superimposition and Registration}

The 3D images were superimposed on the cranial base, which was not altered by the surgical procedure, using the voxel-based superimposition tool in Dolphin. The area of the cranial base to be used for superimposition is defined by a red box in the three slice views. The superimposition was achieved by moving the T3 image on top of the T2 image so that after the superimposition we could create a registered T3 image. The precision of the Dolphin 3D superimposition was then verified using the slice view (axial, sagittal, and coronal views).

Figure 18. Superimposition of $3 \mathrm{D}$ images with the cranial base structures by using Dolphin software. The red boxes indicate the areas of superimposition. A. Axial view; B. Sagittal view; C. Coronal view.
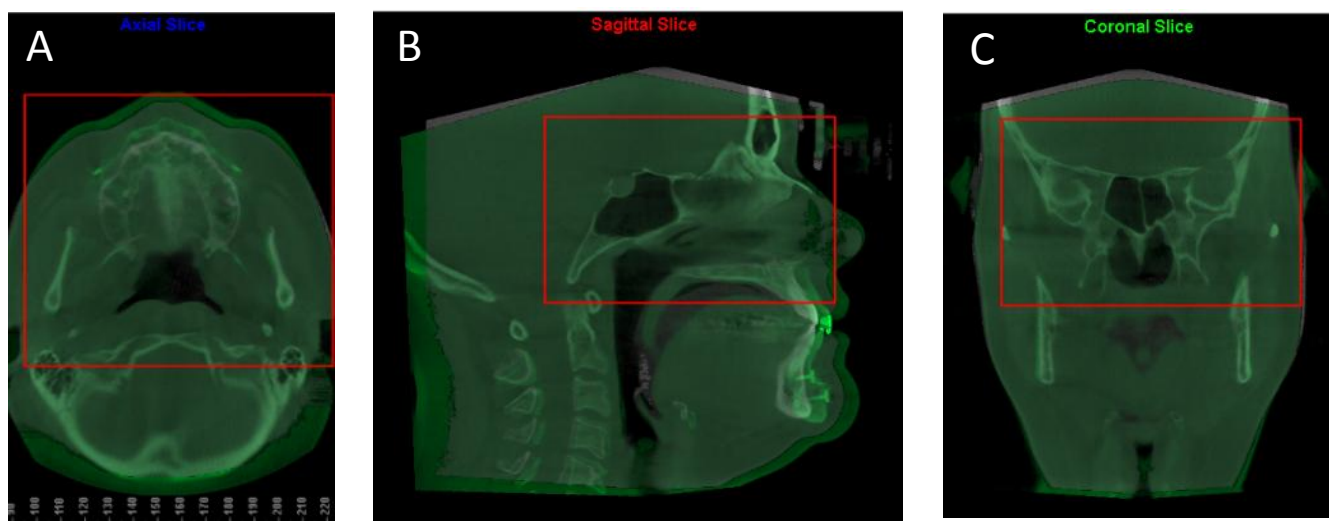
Figure 19. Views of superimpositions (T2, brown; T3, green). A. Frontal view; B. Profile view.
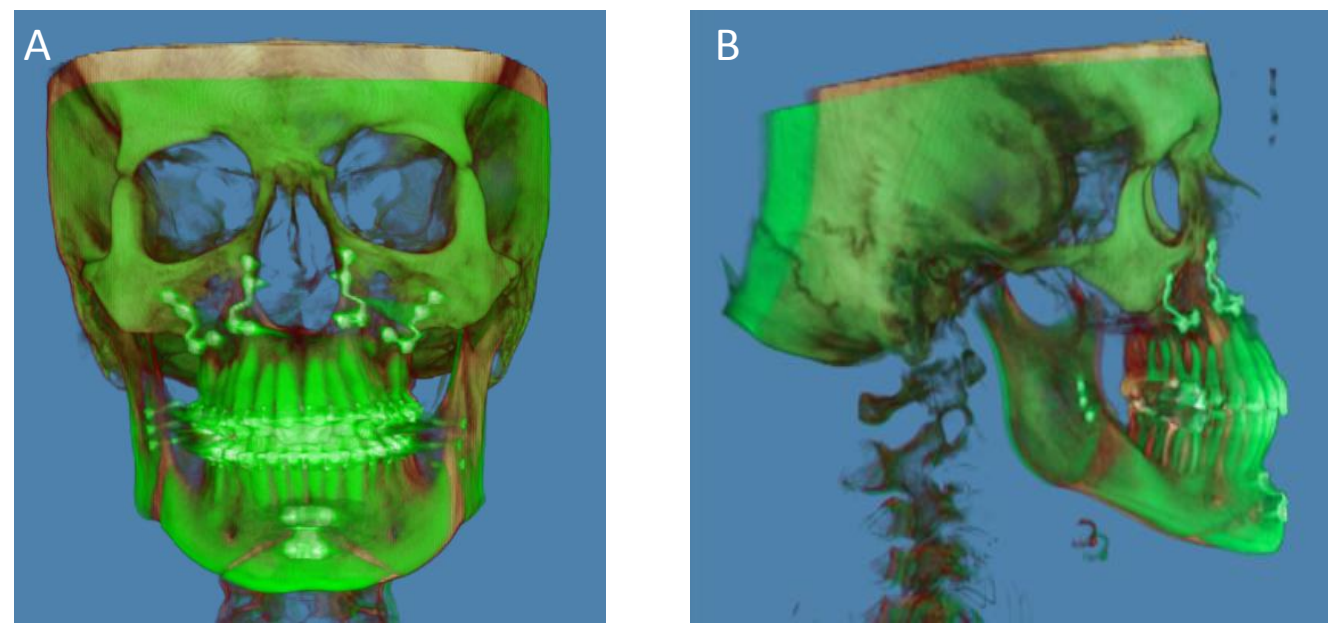

After that, the registered T3 scans from Dolphin were exported as DICOM files, and ITKSNAP software was used to convert the file format to Guys Image Processing Lab (GIPL) format.

\section{Image Segmentation}

3D Slicer was then used to segment the entire skull using the Intensity Segmenter tool (the same intensity range of 550 was used for all subjects to eliminate any possible error due to the segmentation process) so that a surface model of registered T3 was created for each patient.

Since the registered T3 images from the two software packages have the same coordinate system as that of $\mathrm{T} 2$, they would line up perfectly if there was no difference in the superimposition technique in both software packages.

\section{Model Construction}

In the ITK-SNAP software, automatic segmentation was performed for each CBCT volume. The 3D virtual surface model of the skull generated was then exported as a GIPL format. 


\section{Quantitative Measurements}

Quantification of the differences was done by measuring the distance between the two surface models, using closest-point color maps.

Figure 20. Three-dimensional color map of the registered T3 models showing the differences in millimeters.

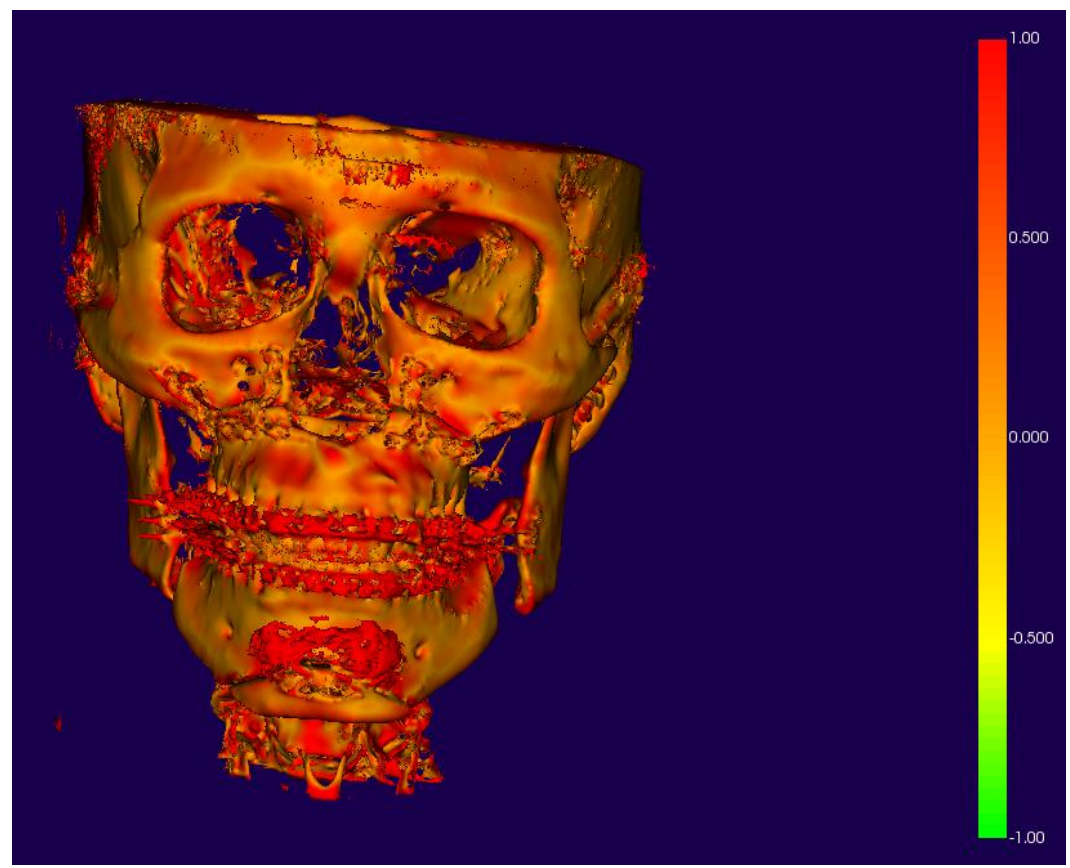

Three areas were selected using the Pick'n Paint tool in 3D Slicer to measure the absolute differences between the two models after the surgery. The three areas were A-point, B-point, and Pogonion point. After defining these areas with the Pick'n Paint tool, the Mesh Stats tool was used to calculate the absolute differences in millimeters between the two 3D surfaces.

Figure 21. Fiducial areas were selected using the Pick'n Paint tool in 3D Slicer. 


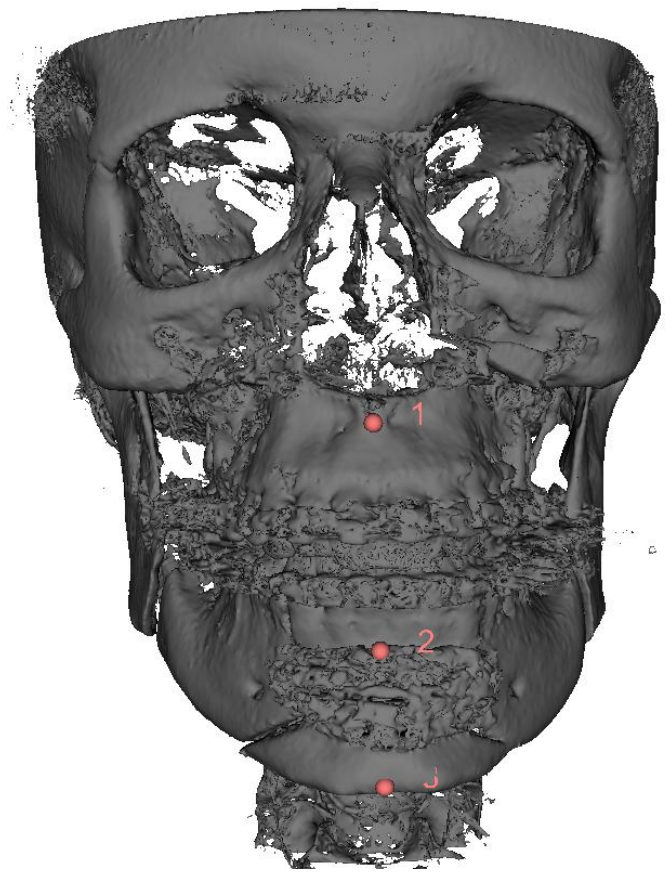

The following reference points were used to analyze the 3D skeletal measurements:

- A: The most concave point of anterior maxilla.

- B: The most concave point on mandibular symphysis.

- Pogonion: The most anterior point of mandibular symphysis.

This process was performed and repeated for each patient at (T3 and T4) as well to assess the relapse after the surgery.

Table 1: Software programs used in this study.

\begin{tabular}{|l|l|l|}
\hline Software & \multicolumn{2}{|c|}{ Purpose } \\
\hline Dolphin & Superimposition process & $\begin{array}{l}\text { Registration of different CBCTs at the anterior cranial } \\
\text { base. }\end{array}$ \\
\hline ITK-Snap & Superimposition evaluation & $\begin{array}{l}\text { Construction of 3D surface models using DICOM files } \\
\text { and export as GIPL. }\end{array}$ \\
\hline 3D Slicer & Superimposition evaluation & $\begin{array}{l}\text { Provided closest point color maps between registered } \\
\text { 3D surface models. }\end{array}$ \\
\hline
\end{tabular}

\section{Method Error}


The reliability of this three-dimensional airway and skeletal analysis is tested by investigating the error in locating and measuring the changes of all landmarks. Fifteen (\%60) randomly selected subjects are analyzed a second time two weeks after the initial measurements. For all variables, differences between the measurements recorded at the first analysis and measurements recorded at the second analysis are compared for each of the 15 individuals. Intra-class correlation coefficients were calculated to evaluate the reliability of the repeated measurements. All statistical tests were two-sided and p-value <.05 were considered statistically significant.

\section{Statistical Analysis}

All statistical tests were performed using SAS (version 9.4, 2013, SAS institute Inc., Cary, NC). Descriptive analyses were conducted to get the basic understanding of the study sample. To determine the changes in airway measurements between different time points and then adjusted for age, gender, duration of follow-up, and GTA, we utilized mixed model analysis. Tukey's test was followed to compare individual measurement means. The significant cut-off value for the Bonferroni correction test was set to 0.008 (0.05 per 6). We incorporated paired t-test and Wilcoxon signed rank test to examine the significance of the amount of advancement and relapse in skeletal change. To compare the difference in skeletal advancement and relapse between age group, gender, duration of follow-up group, and GTA status, we conducted the two-sample t-test and Wilcoxon rank sum test. Mixed model analysis was also performed to evaluate the skeletal relapse adjusted for all covariates. We used Pearson and Spearman correlation tests to evaluate the relationship between airway changes and skeletal changes. Intra-class correlation coefficients were calculated to evaluate the reliability of the repeated measurements. All statistical tests were two-sided and p-value <.05 were considered statistically significant. 


\section{CHAPTER 4: RESULTS}

\section{Patients Characteristics}

A total of 25 Caucasians patients (18 females and 7 males) who were evaluated for OSAS and underwent MMA surgical treatment between 2011 and 2016 were included in the study. Fifteen (10 females and 5 males) of these patients underwent MMA with GTA procedures. The age range of the sample was between 15 and 62 years (mean $37.1 \pm 17.3$ ).

Table 2: Characteristics of experimental subjects $(n=25)$.

\begin{tabular}{|c|c|}
\hline \multicolumn{2}{|c|}{ Characteristics } \\
\hline \multicolumn{2}{|c|}{ Age group (\%) } \\
\hline Mean age \pm SD (years) & $37.1 \pm 17.3$ \\
\hline$\leq 44$ & $13(52.0)$ \\
\hline$>44$ & $12(48.0)$ \\
\hline \multicolumn{2}{|c|}{ Gender n (\%) } \\
\hline Male & $7(28.0)$ \\
\hline Female & $18(72.0)$ \\
\hline \multicolumn{2}{|c|}{ Duration of follow-up n (\%) } \\
\hline$\leq 6$ months & $12(48.0)$ \\
\hline$>6$ months & $13(52.0)$ \\
\hline \multicolumn{2}{|c|}{ GTA $\mathrm{n}(\%)$} \\
\hline Yes & $15(60.0)$ \\
\hline No & $10(40.0)$ \\
\hline
\end{tabular}

\section{Method Error Result}


The reliability coefficient was found to determine the repeatability of the measures made for the variables in this study. When we have two measurements, the coefficient of reliability is the correlation between the first and second measurements. There is high reliability if the correlation is close to one. For all variables the correlation is 0.94 to 0.99 (Table 3). Intra-class correlation coefficients show a high level of agreement between the two measurements, indicating high reliability.

Table 3. Reliability Coefficient.

\begin{tabular}{|l|c|}
\hline \multicolumn{1}{|c|}{ Variables } & Intra-class correlation coefficient \\
\hline Total airway volume & 0.95 \\
\hline Airway area & 0.94 \\
\hline Minimum airway area & 0.97 \\
\hline Skeletal Advancement at Point A & 0.97 \\
\hline Skeletal Advancement at Point B & 0.99 \\
\hline Skeletal Advancement at Point Pog. & 0.99 \\
\hline Skeletal Advancement at Point A at follow-up & 0.96 \\
\hline Skeletal Advancement at Point B at follow-up & 0.98 \\
\hline Skeletal Advancement at Point Pog. at follow-up & 0.99 \\
\hline
\end{tabular}

\section{Airway Change: All subjects in different time points}

When all subjects were grouped together the P-vlaues show significant changes for total airway volume, airway area and minimal axial area between all the time points and time periods (Table 4, 5).

\section{1) Pre-surgical Orthodontic Changes (T2-T1)}


a) For TAV: in the quantitative analysis of the CBCT images at T1, a mean total volume of $11,886.12 \mathrm{~mm}^{3}$ was found for PAS in the patients assessed. At T2, the mean total volume slightly increased to $13191.20 \mathrm{~mm}^{3}$ after the pre-surgical orthodontic phase, which represents a gain of $9.89 \%$ in TAV in comparison with T1.

b) For AA: at T1, the mean was $521.08 \mathrm{~mm}^{2}$. At $\mathrm{T} 2$, the mean increased to $558.84 \mathrm{~mm}^{2}$, which represents a gain of $6.76 \%$ in AA in comparison with $\mathrm{T} 1$.

c) For MAA: at $\mathrm{T} 1$ the mean was $122.24 \mathrm{~mm}^{2}$. At $\mathrm{T} 2$, the mean increased to 124.84 $\mathrm{mm}^{2}$, which represents a gain of $2.08 \%$ in MAA in comparison with $\mathrm{T} 1$.

The (T2-T1) period showed statistically significant difference with $\mathrm{p}$-value $<0.001$ in TAV and AA only, indicating that the pre-surgical orthodontic phase cause slight gain in TAV, and AA.

\section{2) Immediate Post-surgical Changes (T3-T2)}

a) For TAV: at T2, a mean total volume of $13191.20 \mathrm{~mm}^{3}$ was found for PAS in the patients assessed. At T3, the mean total volume increased to $22,210.88 \mathrm{~mm}^{3}$ after the MMA, which represents a gain of $40.61 \%$ in TAV in comparison with T2.

b) For AA: at T2, the mean was $558.84 \mathrm{~mm}^{2}$. At T3, the mean increased to $784.52 \mathrm{~mm}^{2}$, which represents a gain of $28.77 \%$ in AA in comparison with T2.

c) For MAA: at $\mathrm{T} 2$ the mean was $124.84 \mathrm{~mm}^{2}$. At $\mathrm{T} 3$, the mean increased to 286.36 $\mathrm{mm}^{2}$, which represents a gain of $56.40 \%$ in MAA in comparison with T2. 
The (T3-T2) period showed significant difference with p-value $<0.001$ in TAV, AA and MAA, indicating that the MMA promoted real volumetric and planner gain in PAS immediately after surgery.

\section{3) Late Postsurgical Changes (T4-T1) and Follow-up (T4-T3)}

a) For TAV: at the follow-up period (T4), the mean total volume of PAS was 18,511.72 $\mathrm{mm}^{3}$, which represents a mean increase of $6,625.62 \mathrm{~mm}^{3}$ with a gain of approximately $35.8 \%$ in comparison with $\mathrm{T} 1$, but it also represents a loss of 3699.16 $\mathrm{mm}^{3}$ in comparison with $\mathrm{T} 3$, which totals a loss of $20 \%$ in TAV at T3.

b) For AA: at $\mathrm{T} 4$, the mean was $715.04 \mathrm{~mm}^{2}$, which represents a mean increase of $193.96 \mathrm{~mm}^{2}$ with a gain of approximately $27.1 \%$ in comparison with $\mathrm{T} 1$, but it also represents a loss of $69.48 \mathrm{~mm}^{2}$ in comparison with $\mathrm{T} 3$, which totals a loss of $9.7 \%$ in AA at T3.

c) For MAA: at $\mathrm{T} 4$, the mean was $225.88 \mathrm{~mm}^{2}$, which represents a mean increase of $103.64 \mathrm{~mm}^{2}$ with a gain of approximately $45.9 \%$ in comparison with $\mathrm{T} 1$, but it also represents a loss of $60.48 \mathrm{~mm}^{2}$ in comparison with $\mathrm{T} 3$, which totals a loss of $26.8 \%$ in MAA at T3.

When assessing the (T4-T1) period, there was statistically significant difference between groups T4 and T1 with p-value $<0.001$, indicating the efficacy of MMA in increasing the airway space even in the late assessment period.

The (T4-T3) period showed significant difference was with $\mathrm{p}$-value of $<0.001$, which indicates that there is a loss in TAV, AA and MAA at the follow-up period.

Table 4: Changes in airway measurements among different time points $(n=25)$. 


\begin{tabular}{|c|c|c|c|c|c|c|c|c|c|}
\hline \multirow[t]{2}{*}{ Variables } & \multicolumn{2}{|c|}{$\begin{array}{c}\text { Initial } \\
\text { (T1) }\end{array}$} & \multicolumn{2}{|c|}{$\begin{array}{l}\text { Pre-surgical } \\
\text { (T2) }\end{array}$} & \multicolumn{2}{|c|}{$\begin{array}{c}\text { Post-surgical } \\
\text { (T3) }\end{array}$} & \multicolumn{2}{|c|}{$\begin{array}{c}\text { Follow-up } \\
\text { (T4) }\end{array}$} & \multirow[t]{2}{*}{ p-valuef } \\
\hline & LS Mean & $\begin{array}{c}\text { Std } \\
\text { error }\end{array}$ & LS Mean & $\begin{array}{c}\text { Std } \\
\text { error }\end{array}$ & LS Mean & $\begin{array}{c}\text { Std } \\
\text { error }\end{array}$ & LS Mean & $\begin{array}{c}\text { Std } \\
\text { error }\end{array}$ & \\
\hline TAV $\mathbf{~ m m}^{3}$ & ${ }_{\mathrm{abc}}^{11886.12}$ & 976.39 & $\underset{\text { ade }}{13191.20}$ & 962.67 & $\underset{\text { bdf }}{22210.88}$ & 1198.35 & $\underset{\text { cef }}{18511.72}$ & 1344.20 & $<.0001 * * *$ \\
\hline $\mathbf{A A ~ m m ^ { 2 }}$ & $521.08^{\mathrm{abc}}$ & 27.66 & $558.84^{\text {ade }}$ & 28.13 & $784.52^{\text {bdf }}$ & 31.23 & $715.04^{\mathrm{cef}}$ & 32.12 & $<.0001 * * *$ \\
\hline MAA $\mathbf{m m}^{2}$ & $122.24^{\mathrm{bc}}$ & 14.59 & $124.84^{\mathrm{de}}$ & 13.08 & $286.36^{\mathrm{bdf}}$ & 17.62 & $225.88^{\mathrm{cef}}$ & 20.90 & $<.0001 * * *$ \\
\hline
\end{tabular}

Note. $\mathrm{TAV}=$ total airway volume, $\mathrm{AA}=$ airway area, MAA= minimal airway area, LS Mean=Least Square Means, Std error=Standard error.

I p-value from mixed model analysis. $* \mathrm{p}<0.05, * * \mathrm{p}<0.01, * * * \mathrm{p}$-value $<0.001$. Bonferroni correction sets the significant cut-off at $0.008(0.05 / 6)$.

${ }^{\text {a }}$ Significant p-value for comparison between T1 and T2, ${ }^{\mathrm{b}}$ Significant p-value for comparison between $\mathrm{T} 1$ and T3, ${ }^{\mathrm{c}}$ Significant p-value for comparison between $\mathrm{T} 1$ and $\mathrm{T} 4,{ }^{\mathrm{d}}$ Significant $\mathrm{p}$-value for comparison between $\mathrm{T} 2$ and $\mathrm{T} 3,{ }^{\mathrm{e}}$ Significant $\mathrm{p}$-value for comparison between $\mathrm{T} 2$ and $\mathrm{T} 4,{ }^{\mathrm{f}}$ Significant $\mathrm{p}$-value for comparison between $\mathrm{T} 3$ and $\mathrm{T} 4$.

Table 5: Changes in airway measurements among different time periods

\begin{tabular}{|l|c|c|c|c|c|}
\hline \multirow{2}{*}{ Variables } & \multicolumn{2}{|c|}{ (T3-T2) - (T2-T1) } & \multicolumn{2}{c|}{ (T3-T2) - (T3-T4) } & p-value $^{\mathbf{a}}$ \\
\cline { 2 - 6 } & Mean & SD & Mean & SD & \\
\hline AV mm & 7714.60 & 5319.00 & 5320.52 & 4163.00 & $<.0001 * * *$ \\
\hline AA $\mathbf{~ m m}^{2}$ & 187.92 & 172.52 & 156.20 & 109.46 & $<.0001 * * *$ \\
\hline MAA mm & 158.92 & 114.41 & 101.04 & 91.76 & $<.0001 * * *$ \\
\hline
\end{tabular}

${ }^{\mathrm{a}} \mathrm{p}$-value from paired t test. ${ }^{*} \mathrm{p}<0.05, * * \mathrm{p}<0.01, * * * \mathrm{p}<0.001$

\section{Airway Change: in Different Groups}

\section{Younger vs. Older Patients}

The subjects were divided according to age into two groups. The younger age group consisted of individuals whose age ranged from 15-44 years and had an $n=13$. The older age group included subjects that were between the ages of $45-62$ years and had an $n=12$. The p-value for both groups in all variables was $>0.05$ (Table 6). P-values show no significant differences in airway measurements between younger and older patients. 


\section{Males vs. Females}

The subjects were divided according to gender into two groups. The female group was the larger of the two groups with an $n=18$, while the male group consisted of an $n=7$. The p-value for both groups in all variables was $>0.05$ (Table 6). P-values show no significant differences in airway measurements between the males and females.

\section{Duration of Follow-Up}

The subjects were divided according to the duration of follow-up. The first group was followed for 6 months or less with an $n=12$. The second group was followed for more than 6 months with an $n=13$. The $p$-value for both groups in all variables was $>0.05$ (Table 6). P-values show no significant differences in airway measurements between the two follow-up groups.

\section{MMA with or without GTA}

The subjects were also divided into two groups depending on whether or not they received a GTA with their MMA surgery. The group that had MMA with a GTA surgery was the larger of the two groups with an $n=15$. While the group that have MMA surgery only had an $\mathrm{n}=10$. The $\mathrm{p}$-value for both groups in all variables was $>0.05$ (Table 6 ). Pvalues show no significant differences in airway measurements with or without GTA procedure.

Table 6: Mixed model analysis of airway changes. Test of main effect for time adjusted for age group (model 1), gender (model 2), duration of follow-up (model 3), GTA status (model 4), and all covariates together (Model 5).

\begin{tabular}{|l|c|c|c|}
\hline Model & TAV $\mathbf{~ m m}^{3}$ & AA $\mathbf{~ m m}^{2}$ & MAA $\mathbf{~ m m}^{2}$ \\
\hline
\end{tabular}




\begin{tabular}{|c|c|c|c|c|c|c|}
\hline & $F^{a}$ & $\mathbf{P}^{b}$ & $\mathbf{F}^{\mathrm{a}}$ & $\mathbf{P}^{b}$ & $F^{a}$ & $\mathbf{P}^{b}$ \\
\hline \multicolumn{7}{|l|}{ Model 1} \\
\hline Time $(\mathrm{df}=3)$ & 41.82 & $<0.0001 * * *$ & 24.74 & $<0.0001 * * *$ & 35.66 & $<0.0001 * * *$ \\
\hline Age group $(\mathrm{df}=1)$ & 1.48 & .24 & 0.00 & 0.97 & 0.72 & 0.41 \\
\hline \multicolumn{7}{|l|}{ Model 2} \\
\hline Time $(\mathrm{df}=3)$ & 41.82 & $<.0001 * * *$ & 24.74 & $<0.0001 * * *$ & 35.66 & $<0.0001 * * *$ \\
\hline Gender $(\mathrm{df}=1)$ & 0.12 & 0.73 & 0.23 & 0.64 & 0.06 & 0.80 \\
\hline \multicolumn{7}{|l|}{ Model 3} \\
\hline Time $(\mathrm{df}=3)$ & 41.82 & $<0.0001 * * *$ & 24.74 & $<0.0001 * * *$ & 35.66 & $<0.0001 * * *$ \\
\hline $\begin{array}{l}\text { Duration of } \\
\text { follow-up }(\mathrm{df}=1)\end{array}$ & 1.26 & 0.27 & 0.90 & 0.35 & 0.27 & 0.61 \\
\hline \multicolumn{7}{|l|}{ Model 4} \\
\hline Time $(\mathrm{df}=3)$ & 41.82 & $<0.0001 * * *$ & 24.74 & $<0.0001 * * *$ & 35.66 & $<0.0001 * * *$ \\
\hline GTA $(\mathrm{df}=1)$ & 2.35 & 0.14 & 2.79 & 0.11 & 1.47 & 0.24 \\
\hline \multicolumn{7}{|l|}{ Model 5} \\
\hline Time $(\mathrm{df}=3)$ & 41.82 & $<0.0001 * * *$ & 24.74 & $<0.0001 * * *$ & 35.66 & $<0.0001 * * *$ \\
\hline Age Group (df=1) & 0.69 & 0.41 & 0.00 & 0.98 & 0.15 & 0.70 \\
\hline Gender $(\mathrm{df}=1)$ & 0.01 & 0.93 & 0.64 & 0.43 & 0.01 & 0.91 \\
\hline $\begin{array}{l}\text { Duration of } \\
\text { follow-up }\end{array}$ & 0.84 & 0.37 & 0.37 & 0.55 & 0.25 & 0.62 \\
\hline GTA $(\mathrm{df}=1)$ & 0.87 & 0.36 & 1.93 & 0.18 & 0.74 & 0.40 \\
\hline
\end{tabular}

${ }^{\mathrm{a}}$ F-value from F-test

${ }^{\mathrm{b}} \mathrm{p}$-value from the mixed model analysis. ${ }^{*} \mathrm{p}<0.05, * * \mathrm{p}<0.01, * * * \mathrm{p}<0.001$

\section{Skeletal Change: All subjects in different time points}

\section{1) Immediate Postsurgical Changes (T3-T2)}

All of the patients underwent MMA and only fifteen patients had MMA with GTA. At T3, the mean maxillary advancement at point A was $6.56 \mathrm{~mm}$ (range, 3.5-11.2 mm), the mean mandibular advancement at point B was $8.21 \mathrm{~mm}$ (range, 3.7-19.4 $\mathrm{mm}$ ), and the mean chin 
advancement at point Pogonion was $11.42 \mathrm{~mm}$ (range, 3.5-16.3 mm). P-values show a significant difference in the comparison between $\mathrm{T} 2$ and $\mathrm{T} 3$ at all points.

\section{2) Follow-up Changes (T4-T3)}

At T4, the mean relapse at point A was $0.6 \mathrm{~mm}$, the mean relapse at point B was $0.4 \mathrm{~mm}$, and the mean relapse at point Pogonion was $0.6 \mathrm{~mm}$. P-values show a (statistically) significant difference between at (T4-T3) period, which indicates that there is a very minimum (clinical) loss in the amount of advancement at all points (Table 7).

Table 7: Amount of skeletal advancements and relapse $(n=25)$.

\begin{tabular}{|l|c|c|c|c|c|c|}
\hline Variables & \multicolumn{3}{|c|}{$\begin{array}{c}\text { Amount of } \\
\text { Advancement } \\
\text { (T3-T2) }\end{array}$} & \multicolumn{3}{c|}{$\begin{array}{c}\text { Amount of Relapse } \\
\text { (T4-T3) }\end{array}$} \\
\cline { 2 - 7 } & Mean & SD & $\mathrm{p}^{\mathrm{a}}$ & Median & Iqr $^{\mathrm{c}}$ & $\mathrm{P}^{\mathrm{b}}$ \\
\hline Point A & 6.56 & 1.96 & $\begin{array}{c}<0.0001 \\
* * *\end{array}$ & 0.35 & $0.20-0.80$ & $\begin{array}{c}<0.0001 \\
* * *\end{array}$ \\
\hline Point B & 8.21 & 3.21 & $\begin{array}{c}<0.0001 \\
* * *\end{array}$ & 0.30 & $0.10-0.40$ & $\begin{array}{c}0.0005^{*} \\
* *\end{array}$ \\
\hline Point Pog. & 11.42 & 4.12 & $\begin{array}{c}<0.0001 \\
* * *\end{array}$ & 0.35 & $0.10-0.70$ & $\begin{array}{c}<0.0001 \\
* * *\end{array}$ \\
\hline
\end{tabular}

${ }^{a} \mathrm{p}$-value from paired $\mathrm{t}$ test.

${ }^{\mathrm{b}} \mathrm{p}$-value from Wilcoxon signed rank test

${ }^{\mathrm{c}}$ iqr $=$ Interquartile range

${ }^{*} \mathrm{p}<0.05, * * \mathrm{p}<0.01, * * * \mathrm{p}<0.001$.

\section{Skeletal Changes: in Different Groups}

1) Skeletal Advancement (T3-T1)

Younger vs. Older Patients 
There was a significant difference in the amount of skeletal advancement between age groups at point A. Older group had more increase $(7.6 \mathrm{vs} .5 .52 \mathrm{~mm})$ at point A than younger group (Table 8).

\section{Males vs. Females}

There was a significant difference in the amount of skeletal advancement between gender groups at both point A and Pogonion. Male had more increase at point A (7.87 vs. 6.02 $\mathrm{mm}$ ) and point Pogonion (14.09 vs. $10.32 \mathrm{~mm}$ ) then female (Table 8).

\section{MMA with or without GTA}

There was a no significant difference in the amount of skeletal advancement with or without GTA procedure (Table 8).

Table 8: Amount of skeletal advancements by age, gender, GTA groups $(n=25)$.

\begin{tabular}{|l|c|c|c|c|c|}
\hline \multicolumn{5}{|c|}{ Age Group } \\
\hline Variables & \multicolumn{2}{|c|}{$14-44$} & \multicolumn{2}{|c|}{$\geq 45$} & \multirow{2}{*}{$\mathrm{P}^{\mathrm{a}}$} \\
\cline { 2 - 5 } & Mean & SD & Mean & SD & \\
\hline Point A & 5.52 & 1.53 & 7.60 & 1.83 & $0.006^{* *}$ \\
\hline Point B & 7.10 & 2.35 & 9.32 & 3.65 & 0.09 \\
\hline Point Pog. & 9.87 & 4.09 & 12.98 & 3.71 & 0.06 \\
\hline
\end{tabular}

\begin{tabular}{|l|l|l|l|c|l|}
\hline \multicolumn{5}{|c|}{ Gender } \\
\hline Variables & \multicolumn{2}{|c|}{ Male } & \multicolumn{2}{c|}{ Female } & \multirow{2}{*}{$\mathrm{P}^{\mathrm{a}}$} \\
\cline { 2 - 5 } & Mean & SD & Mean & SD & \\
\hline Point A & 7.87 & 1.88 & 6.02 & 1.77 & $0.03^{*}$ \\
\hline Point B & 8.94 & 2.14 & 7.91 & 3.57 & 0.48 \\
\hline Point Pog. & 14.09 & 1.65 & 10.32 & 4.38 & $0.006^{* *}$ \\
\hline
\end{tabular}




\begin{tabular}{|l|c|c|c|c|c|}
\hline \multicolumn{5}{|c|}{ GTA } \\
\hline Variables & \multicolumn{2}{|c|}{ Yes } & \multicolumn{2}{c|}{ No } & \multirow{2}{*}{ a $^{\mathrm{a}}$} \\
\cline { 2 - 6 } & Mean & SD & Mean & SD & \\
\hline Point A & 12.67 & 3.02 & 9.33 & 5.04 & 0.06 \\
\hline Point B & 7.97 & 2.30 & 8.60 & 4.48 & 0.70 \\
\hline Point Pog. & 6.67 & 2.47 & 6.38 & 2.47 & 0.74 \\
\hline${ }^{a}$ p-values from two sample t test *p $<0.05, * * p<0.01, * * * p<0.001$
\end{tabular}

\section{2) Skeletal Relapse (T4-T3)}

There was no significant difference in the amount of skeletal relapse in age and gender groups, but there was a significant difference in the amount of skeletal relapse between both follow-up and GTA groups at point B (Table 9).

Table 9: Amount of skeletal relapse by age group, gender, follow-up, GTA groups ( $\mathrm{n}=25)$.

\begin{tabular}{|l|l|c|l|c|c|}
\hline \multicolumn{5}{|c|}{ Age Group } \\
\hline Variables & \multicolumn{2}{|c|}{$14-44$} & \multicolumn{2}{c|}{$\geq 45$} & \multirow{2}{*}{ P $^{\mathrm{b}}$} \\
\cline { 2 - 5 } & Median & Iqr $^{\mathrm{a}}$ & Median & iqr & \\
\hline Point A & 0.40 & $0.20-0.80$ & 0.35 & $0.20-0.80$ & 0.88 \\
\hline Point B & 0.35 & $0.10-0.50$ & 0.25 & $0.10-0.30$ & 0.28 \\
\hline Point Pog. & 0.45 & $0.10-0.95$ & 0.15 & $0.10-0.50$ & 0.35 \\
\hline
\end{tabular}

${ }^{a}$ iqr= Interquartile range

${ }^{\mathrm{b}} \mathrm{p}$-values from Wilcoxon rank sum test $* \mathrm{p}<0.05,{ }^{* *} \mathrm{p}<0.01,{ }^{* * *} \mathrm{p}<0.001$

\begin{tabular}{|c|c|c|c|c|c|}
\hline \multicolumn{5}{|c|}{ Gender } \\
\hline Variables & \multicolumn{2}{|c|}{ Male } & \multicolumn{2}{c|}{ Female } & \multirow{2}{*}{$\mathrm{P}^{\mathrm{a}}$} \\
\cline { 2 - 5 } & Median & Iqr & Median & iqr & \\
\hline Point A & 0.30 & $0.20-0.60$ & 0.60 & $0.20-1.40$ & 0.37 \\
\hline Point B & 0.30 & $0-0.40$ & 0.30 & $0.20-1.40$ & 0.48 \\
\hline
\end{tabular}




\begin{tabular}{|c|c|c|c|c|c|}
\hline Point Pog. & 0.20 & $0.10-0.50$ & 0.40 & $0.10-1.20$ & 0.41 \\
\hline
\end{tabular}

${ }^{\mathrm{b}} \mathrm{p}$-values from Wilcoxon rank sum test $* \mathrm{p}<0.05,{ }^{* *} \mathrm{p}<0.01, * * * \mathrm{p}<0.001$

\begin{tabular}{|c|c|c|c|c|c|}
\hline \multicolumn{6}{|c|}{ Duration of follow-up } \\
\hline \multirow[t]{2}{*}{ Variables } & \multicolumn{2}{|c|}{$\begin{array}{c}\leq 6 \text { months } \\
(n=12)\end{array}$} & \multicolumn{2}{|c|}{$\begin{array}{c}>6 \text { months } \\
(n=12)\end{array}$} & \multirow[t]{2}{*}{$\mathrm{P}^{\mathrm{a}}$} \\
\hline & Median & iqr & Median & iqr & \\
\hline Point A & 0.35 & $0.10-0.55$ & 0.45 & $0.25-1.10$ & 0.26 \\
\hline Point B & 0.20 & $0-0.30$ & 0.30 & $0.30-0.70$ & $0.02 *$ \\
\hline Point Pog. & 0.10 & $0.10-0.55$ & 0.40 & $0.15-1.00$ & 0.21 \\
\hline
\end{tabular}

${ }^{\mathrm{a}}$ iqr= Interquartile range

${ }^{\mathrm{b}} \mathrm{p}$-values from Wilcoxon rank sum test $* \mathrm{p}<0.05,{ }^{* *} \mathrm{p}<0.01, * * * \mathrm{p}<0.001$

\begin{tabular}{|l|l|c|l|c|l|}
\hline \multicolumn{5}{|c|}{ GTA } \\
\cline { 1 - 5 } Variables & \multicolumn{2}{|c|}{ Yes } & \multicolumn{2}{c|}{ No } & \multirow{2}{*}{ P $^{\mathrm{a}}$} \\
\cline { 2 - 5 } & Median & iqr & Median & Iqr & \\
\hline Point A & 0.30 & $0.10-0.50$ & 0.50 & $0.20-1.00$ & 0.22 \\
\hline Point B & 0 & $0-0.20$ & 0.30 & $0.30-0.40$ & $0.008^{* *}$ \\
\hline Point Pog. & 0.10 & $0.10-0.50$ & 0.40 & $0.10-1.10$ & 0.16 \\
\hline
\end{tabular}

${ }^{\mathrm{a}}$ iqr= Interquartile range

${ }^{\mathrm{b}} \mathrm{p}$-values from Wilcoxon rank sum test $* \mathrm{p}<0.05, * * \mathrm{p}<0.01, * * * \mathrm{p}<0.001$

P-values show significant effect for time at point A, point B, and point Pogonion But not for all other covariates (Table 10).

Table 10: Mixed model analysis for amount of skeletal relapse. Test of main effect for relapse adjusted for all covariates together (Model 5).

\begin{tabular}{|l|l|l|l|}
\hline \multirow{3}{*}{ Model } & \multicolumn{3}{|c|}{ Skeletal relapse } \\
\cline { 2 - 4 } & Point A & Point B & Point Pog. \\
\hline
\end{tabular}




\begin{tabular}{|l|l|l|l|l|l|l|}
\hline & $\mathbf{F}^{\mathbf{a}}$ & $\mathbf{P}^{\mathbf{b}}$ & $\mathbf{F}^{\mathbf{a}}$ & $\mathbf{P}^{\mathbf{b}}$ & $\mathbf{F}^{\mathbf{a}}$ & $\mathbf{P}^{\mathbf{b}}$ \\
\hline Time (df=1) & 19.45 & $0.0002^{* * *}$ & 7.17 & $0.01^{*}$ & 13.04 & $0.002^{* *}$ \\
\hline $\begin{array}{l}\text { Age group } \\
\text { (df=1) }\end{array}$ & 14.80 & $0.001^{* *}$ & 4.52 & $0.04 *$ & 2.51 & 0.13 \\
\hline Gender (df=1) & 3.63 & 0.07 & 0.00 & 0.96 & 3.05 & 0.10 \\
\hline $\begin{array}{l}\text { Follow-up } \\
\text { month (df=1) }\end{array}$ & 2.28 & 0.15 & 0.05 & 0.82 & 0.03 & 0.86 \\
\hline GTA (df=1) & 2.32 & 0.14 & 2.01 & 0.17 & 1.36 & 0.26 \\
\hline
\end{tabular}

${ }^{\text {a }} \mathrm{F}$ values from $\mathrm{F}$ test

${ }^{\mathrm{b}} \mathrm{p}$-values from mixed model analysis. ${ }^{*} \mathrm{p}<0.05,{ }^{* *} \mathrm{p}<0.01,{ }^{* * *} \mathrm{p}<0.001$

\section{Correlation of Amount of Skeletal advancement and Oropharyngeal Airway}

\section{Measurements}

When correlating the amount of skeletal advancement with the oropharyngeal airway changes immediately after surgery (T3), there was no significant correlation found (Table 11).

Table 11: Pearson correlation test for association between airway measurements at $\mathrm{T} 3$ and skeletal advancement

\begin{tabular}{|c|c|c|c|}
\hline \multirow{2}{*}{ Variables } & \multicolumn{3}{|c|}{ Pearson Correlation Coefficients } \\
& \multicolumn{3}{|c|}{ P-value } \\
\cline { 2 - 4 } & $\begin{array}{c}\text { Point A } \\
\text { advancement }\end{array}$ & $\begin{array}{c}\text { Point B } \\
\text { advancement }\end{array}$ & $\begin{array}{c}\text { Point Pog. } \\
\text { Advancement }\end{array}$ \\
\hline AV & 0.13 & 0.12 & -0.08 \\
& $\mathbf{0 . 5 6}$ & $\mathbf{0 . 5 7}$ & $\mathbf{0 . 7 2}$ \\
\hline AA & 0.19 & 0.08 & -0.06 \\
& $\mathbf{0 . 3 6}$ & $\mathbf{0 . 7 1}$ & $\mathbf{0 . 7 9}$ \\
\hline MAA & 0.13 & 0.16 & 0.09 \\
& $\mathbf{0 . 5 5}$ & $\mathbf{0 . 4 4}$ & $\mathbf{0 . 6 7}$ \\
\hline
\end{tabular}

Correlation of Amount of Skeletal Relapse and Oropharyngeal Airway Measurements 
When correlating the amount of skeletal relapse with the oropharyngeal airway changes at the follow-up period (T4), there was no significant correlation found except for MAA measurement at point B. (Table 12).

Table 12: Spearman correlation test for association between airway measurements at T4 and skeletal relapse

\begin{tabular}{|c|c|c|c|}
\hline \multirow{2}{*}{ Variables } & \multicolumn{3}{|c|}{ Spearman Correlation Coefficients } \\
& \multicolumn{3}{|c|}{ P-value } \\
\cline { 2 - 4 } & Point A relapse & Point B relapse & Point Pog. relapse \\
\hline AV & 0.05 & -0.20 & -0.25 \\
& $\mathbf{0 . 8 1}$ & $\mathbf{0 . 3 4}$ & $\mathbf{0 . 2 5}$ \\
\hline AA & 0.12 & -0.15 & -0.34 \\
& $\mathbf{0 . 5 9}$ & $\mathbf{0 . 5 0}$ & $\mathbf{0 . 1 0}$ \\
\hline MAA & -0.08 & -0.43 & -0.27 \\
& $\mathbf{0 . 7 1}$ & $\mathbf{0 . 0 4} *$ & $\mathbf{0 . 2 1}$ \\
\hline
\end{tabular}




\section{CHAPTER 5: DISCUSSION}

\section{Airway Changes: All Subjects in Different Time Points}

Pre-surgical orthodontic treatment for an average of 18 months (T2-T1) resulted in slight but significant increase in oropharyngeal space (TAV, 9.89\%, and AA 6.76\%). Further increase in airway volume was obtained with MMA procedure (TAV, 40.61\%, AA, 28.77\% and MAA, $56.40 \%$ ) during the period T3-T2. This results that showed immediate significant 3D increase in the airway space after MMA agreed with previous studies. Raffini et. al., ${ }^{40}$ found significant increase in the PAS with (TAV, 56\%, AA, 34\% and MAA, 112\%) immediately after MMA surgery in 10 patients with skeletal class II and without OSA. Similar study was done by Goncalves et. al., ${ }^{19}$ who found significant immediate 3D airway space increase in 30 female patients after MMA counterclockwise rotation and mandibular advancement with TMJ Concepts total joint prostheses.

During the average of 10 months follow-up observation period (T4-T3) period, a decrease in pharyngeal airway space (TAV, 20\%; AA 9.7\%; MAA 26.8\%) was found. This is consistent with a recent study by Carvalho et. al., ${ }^{20}$ which affirmed that MMA allowed great linear area and volume increase in PAS in the immediate and late postoperative periods, but there was partial loss of the increased space after 6 months. Oedema is an important factor in the evaluation of airway space, particularly in the immediate postoperative period of MMA. Apparently, the oedema in airways may have masked the real gain in airway space in the immediate period and it became more perceptible in the late period after the oedema regressed.

According to Riley et. al. ${ }^{34}$ additional data analysis showed that after the initial enlargement of the PAS, soft tissue relapse would occur during the first 12 months and then stabilize. A similar finding was noted by Yao et al. possible explanations include the concept that lateral 
pharyngeal wall collapse is a significant contributor to hypopharyngeal obstruction in OSA patients, and skeletal surgery gives support to the lateral pharyngeal through the constrictor muscles.

Another postsurgical evaluation study for PAS after mandibular advancement only for 16 patients with class II done by using acoustic pharyngometry found a significant increase 2 months after surgery in minimum cross-sectional area, mean cross-sectional area and in mean volume. Relapse was also observed 1 year after surgery of the previous airway measurements $12.6 \%, 7.9 \%$ and $3.9 \%$ respectively. ${ }^{52}$

\section{Airway Changes with Subgroups (Age, Gender, GTA procedure)}

During subgroup evaluation, there was no significant difference in airway measurements in age and gender. A relatively small sample size, wide age distribution, and dissimilar gender distribution would limit the ability to use these findings to predict the surgical outcomes according to patient age and gender.

The subjects were also divided into two groups depending on whether or not they received a GTA with their MMA surgery. The group that only had MMA with a GTA surgery was the larger of the two groups. The $\mathrm{p}$-value for both groups in all variables was $>0.05$. This indicates that there are no significant differences in airway measurements with or without GTA procedure. This finding is in concert with a 2D study by Torres et. al., ${ }^{53}$ which found that MMA surgery, with and without advancement genioplasty, can promote immediate gains to the PAS.

\section{Skeletal Changes: All Subjects in Different Time Points}


All of the patients underwent MMA and only fifteen patients had MMA with GTA. Maxillary rigid fixation was achieved with miniplates while the mandible and the chin were fixed with bicortical screws. At T3, the mean maxillary advancement at point A was $6.56 \mathrm{~mm}$ (range, 3.5$11.2 \mathrm{~mm}$ ), the mean mandibular advancement at point B was $8.21 \mathrm{~mm}$ (range, 3.7-19.4 $\mathrm{mm}$ ), and the mean chin advancement at point Pogonion was $11.42 \mathrm{~mm}$ (range, 3.5-16.3 mm). Pvalues show a significant difference in the comparison between $\mathrm{T} 2$ and $\mathrm{T} 3$ at all points. However, Holty and Guilleminault showed that maxillary advancement of approximately 8.4 $\mathrm{mm}( \pm 2.8 \mathrm{~mm})$ led to a success rate of less than $80 \%$, while maxillary advancement of approximately $9.9 \mathrm{~mm}( \pm 1.3 \mathrm{~mm})$ increased the success rate to more than $80 \% .^{34}$ The magnitude of skeletal movements completed in this study was comparable with the other studies. $^{27}$

At T4, the mean relapse at point A was $0.6 \mathrm{~mm}$, the mean relapse at point B was $0.4 \mathrm{~mm}$, and the mean relapse at point Pogonion was $0.6 \mathrm{~mm}$. P-values show a (statistically) significant difference between time intervals $\mathrm{T} 3$ and $\mathrm{T} 4$, which proves that there is a very minimum (clinical) loss in the amount of advancement at all points. A change of less than a $1 \mathrm{~mm}$ was (statistically) significant. However, this change appears to be (clinically) insignificant. This should be regarded in the same light as standards established by Proffit et. al., ${ }^{54}$ who considered changes of $<2 \mathrm{~mm}$ within the range of method error and clinically insignificant. This finding indicate that even though there was statistically significant difference between T4 and T3 suggesting skeletal relapse, the mean difference was less than $1 \mathrm{~mm}$ which is hard to detect clinically. That means all surgical movements (T3-T2) remained stable during the follow-up period (T4-T3) agreeing with previous studies. ${ }^{19,55,41,30}$ 
Furthermore, Nojan et. al., ${ }^{56}$ found that there is no significant relapse after genioplasty and bilateral sagittal split osteotomy or genioplasty alone after 12 months when rigid internal fixation is used. The changes were minimal and hard to detect clinically.

\section{Skeletal Changes with subgroups (Age, Gender, GTA procedure)}

During subgroup evaluation, there was a significant difference in the amount of skeletal advancement between age groups at point A. Older patients had more advancement (7.6 vs.5.52 $\mathrm{mm})$ at point $\mathrm{A}$ than younger patients. This may reflect the skeletal remodeling in the A point. ${ }^{41}$ Or it could be that this amount of advancement was planned already by the provider.

There was a significant difference in the amount of skeletal advancement between gender groups at both point A and point Pogonion. Male had more increase at point A (7.87 vs. 6.02 $\mathrm{mm}$ ) and point Pogonion (14.09 vs. $10.32 \mathrm{~mm}$ ) than female. This could be due to the small number of males in this study.

There was no significant difference in the amount of skeletal relapse in age and gender groups, but there was a significant difference in the amount of skeletal relapse between followup and GTA groups at point B possibly because point B was affected by the chin advancement.

\section{Correlation between Oropharyngeal Airway Measurements and Surgical Advancement}

When correlating the amount of skeletal advancement with the oropharyngeal airway measurements immediately after surgery, there was no significant correlation found. Which agreed with both Butterfield et. al., ${ }^{57}$ and Riley et. al., ${ }^{58}$ who found that there is no direct relationship between the amount of skeletal advancement and change in airway (PAS) as well. A 
similar finding was noted by Yao et al. Possible explanations include the concept that lateral pharyngeal wall collapse is a significant contributor to hypopharyngeal obstruction in OSA patients, and skeletal surgery gives support to the lateral pharyngeal through the constrictor muscles. ${ }^{58}$. Another 2-dimesional study by Susarla et. al., ${ }^{59}$ stated that "With regard to the lack of a dose-response relation between the magnitude of jaw advancement and changes in cephalometric parameters, it is likely that anatomic changes in the airway are the result of a complex interplay between demographic factors (age, gender, BMI) and surgical factors (magnitude of advancement). Given the small sample evaluated, a dose-response relation could not be appropriately evaluated using a multiple regression model". This is the same case in the current study.

In contrast, Goncalves et. al., ${ }^{19}$ found a positive correlation between the amount of mandibular advancement and increases in airway surface area, airway volume, lateral dimension of the retroglossal airway and antero-posterior dimension of the retroglossal airway. Thus, the greater the mandibular advancement, the greater the dimensional airway increase.

\section{Correlation between Oropharyngeal Airway Measurements and Surgical Relapse}

When correlating the amount of skeletal relapse with the airway changes at the follow-up period, there was no significant correlation found except for MAA measurement at point B possibly because point B was affected the most by the chin advancement. This is in agreement with a $2 \mathrm{D}$ study by $\operatorname{Tiner}^{21}$ et. al., found that there was no significant correlation between the amount of surgical advancement and the amount of postsurgical instability. Moreover, Nojan et. al., ${ }^{56}$ found that relapse rate for geniolasty was not statistically related to the amount of 
advancement. However, the skeletal relapse in the current study was clinically insignificant that led to no effect of the amount of skeletal relapse on the oropharyngeal airway measurements.

\section{Limitations of Study}

Limitations of the study included a small number of total subjects $(n=25)$ limited to the subjects in the database of New Hope Orthodontics, which is the private practice of Dr. Mary E. Burns. This represents the greatest weakness of this study and limits the ability to compare changes in outcomes between subgroup analyses. Moreover, there was variation in medical history, age, gender, BMI, severity of malocclusion and OSAS among the subjects. Although $\mathrm{CBCT}$ is a tremendous tool in evaluating airway parameters, it does have limitations that include:

1. It is a static evaluation of a dynamic structure,

2. Airway dimensions have been shown to change depending on the stage of the breathing,

3. Scans were taken in an upright position. The airway volume has been demonstrated to change when a patient is in a supine position,

4. Scans had artifacts from subject movements, brackets, surgical splints, plates, screws and machine specifications. 


\section{CHAPTER 6: SUMMARY AND CONCLUSIONS}

\section{Summary}

The rationale for this study is to gain a better understanding of the airway changes in OSA patients treated with MMA procedure with or without GTA. In addition, this study determines if there is a relationship between anteroposterior skeletal changes with airway changes and the stability after MMA procedure.

This study was in collaboration with New Hope Orthodontics, which is the private practice of Dr. Mary E. Burns. A total of 25 subjects pre- and post-surgical CBCT scans were evaluated. All of the individuals underwent maxillomandibular advancement with or without GTA surgery. All DICOM files were analyzed using Dolphin 3D Imaging 11.95, ITK-SNAP and 3D Slicer software programs. CBCT images were used to find airway measurements; total airway volume, airway area and minimum axial area at explicit regions along the posterior airway space. Voxelbased 3D superimposition was used to measure the amount of skeletal advancement and relapse.

Based on results discussed in Chapter IV, the following null hypotheses were rejected:

1. There is no significant difference in oropharyngeal airway measurements (TAV, AA and MMA) between pre-surgical orthodontic treatment (T2-T1) and surgical treatment with MMA procedure (T3-T2).

2. There is no significant difference in oropharyngeal airway measurements (TAV, AA and MMA) between surgical treatment with MMA procedure (T3-T2) and the 10 months follow-up observation (T4-T3). 
3. There is no significant difference in the amount of skeletal advancements (A-Point; BPoint; and Pogonion) with MMA treatment.

And the following null hypotheses were accepted:

1. There is no significant difference in oropharyngeal airway measurements for surgery with or without GTA procedure.

2. There is no significant correlation between the amounts of skeletal advancement and the change in oropharyngeal airway measurements with MMA procedure.

3. There is no significant correlation between the amounts of skeletal changes 10 months after MMA procedure with the change in oropharyngeal airway measurements.

\section{Conclusions}

Significant increase in oropharyngeal space can be expected with MMA surgery with or without GTA procedure in patients diagnosed with OSA. Significant forward movement of the maxilla, mandible and chin positions can be obtained with MMA procedure. A partial loss in the increase in oropharyngeal space (TAV, 20\%; AA 9.7\%; MAA 26.8\%) was found during the 10 months follow-up period. The surgical movements were found to be stable with less than $1 \mathrm{~mm}$ of relapse during the 10 months follow-up period, which was not clinically significant.

Figure 22. Example of patient's pre- and post-operative airway and skeletal changes. A. T1;

B. T3.
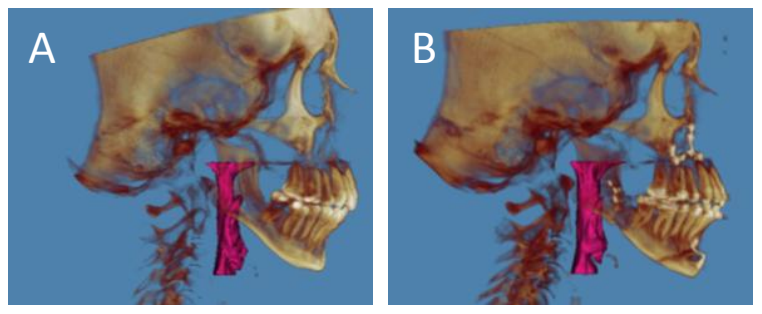


\section{CHAPTER 7: RECOMMENDATIONS FOR FUTURE RESEARCH}

With the rate of obesity continuing to rise in the United States, OSA is a syndrome that is only going to increase with its prevalence. Possible areas of research could include a further long-term follow-up data of the current study. This would help determine the stability of the airway measurements and the skeletal movements after more than 2 years. Another possible study could examine all measurable indexes other than the airway volume and area e.g.; upper airway length and shape. Also, evaluate the airway in different regions; e.g.; retropalatal, nasopharyngeal and hyopharengeal. This would help further identify the segment of the airway that increases the most after MMA surgery. Moreover, studying the outcomes of MMA with regards to OSA improvement based on polysomnograms (PSGs) variables e.g.; respiratory disturbance index [RDI], apnea hypopnea index [AHI], low oxyhemoglobin desaturation [LSAT], and body mass index [BMI] would help to evaluate the clinical success and the improvement of the quality of life of the patient. 


\section{References}

1. Ryan S. Obstructive Sleep Apnea. Int Encycl Public Heal. 2016:308-314. doi:10.1016/B978-0-12-803678-5.00311-8

2. Eckert DJ, Malhotra A, Jordan AS. Mechanisms of Apnea. Prog Cardiovasc Dis. 2009;51(4):313-323. doi:10.1016/j.pcad.2008.02.003

3. Kushida CA, Littner MR, Hirshkowitz M, et al. Practice parameters for the use of continuous and bilevel positive airway pressure devices to treat adult patients with sleeprelated breathing disorders. Sleep. 2006;29(3):375-380. doi:10.1093/sleep/29.3.375

4. Kribbs NB, Pack AI, Kline LR, et al. Objective Measurement of Patterns of Nasal CPAP Use by Patients with Obstructive Sleep Apnea. Am Rev Respir Dis. 1993;147(4):887-895. doi:10.1164/ajrccm/147.4.887

5. Sin DD, Mayers I, Man GCW, Ghahary A, Pawluk L. Can continuous positive airway pressure therapy improve the general health status of patients with obstructive sleep apnea? a clinical effectiveness study. Chest. 2002;122(5):1679-1685. doi:10.1378/chest.122.5.1679

6. Lin HC, Friedman M, Chang HW, Gurpinar B. The efficacy of multilevel surgery of the upper airway in adults with obstructive sleep apnea/hypopnea syndrome. Laryngoscope. 2008;118(5):902-908. doi:10.1097/MLG.0b013e31816422ea

7. Abramson Z, Susarla SM, Lawler M, Bouchard C, Troulis M, Kaban LB. Threedimensional computed tomographic airway analysis of patients with obstructive sleep apnea treated by maxillomandibular advancement. J Oral Maxillofac Surg. 2011;69(3):677-686. doi:10.1016/j.joms.2010.11.037

8. Waite PD, Wooten V, Lachner J, Guyette RF. Maxillomandibular advancement surgery in 23 patients with obstructive sleep apnea syndrome. J Oral Maxillofac Surg. 1989;47(12):1256-1261. doi:10.1016/0278-2391(89)90719-2

9. Ogawa T, Enciso R, Shintaku WH, Clark GT. Evaluation of cross-section airway configuration of obstructive sleep apnea. Oral Surg Oral Med Oral Pathol Oral Radiol Endod. 2007;103(1):102-108. doi:10.1016/j.tripleo.2006.06.008

10. Torres HM, Valladares-Neto J, Torres ÉM, Freitas RZ, Silva MAG. Effect of Genioplasty on the Pharyngeal Airway Space Following Maxillomandibular Advancement Surgery. $J$ Oral Maxillofac Surg. 2017;75(1):189.e1-189.e12. doi:10.1016/j.joms.2016.09.005

11. Aboudara C, Nielsen I, Huang JC, Maki K, Miller AJ, Hatcher D. Comparison of airway space with conventional lateral headfilms and 3-dimensional reconstruction from conebeam computed tomography. Am J Orthod Dentofac Orthop. 2009;135(4):468-479. doi:10.1016/j.ajodo.2007.04.043

12. Tso HH, Lee JS, Huang JC, Maki K, Hatcher D, Miller AJ. Evaluation of the human airway using cone-beam computerized tomography. Oral Surgery, Oral Med Oral Pathol Oral Radiol Endodontology. 2009;108(5):768-776. doi:10.1016/j.tripleo.2009.05.026 
13. Hernández-Alfaro F, Guijarro-Martínez R, Mareque-Bueno J. Effect of mono- and bimaxillary advancement on pharyngeal airway volume: Cone-beam computed tomography evaluation. J Oral Maxillofac Surg. 2011;69(11):e395-e400. doi:10.1016/j.joms.2011.02.138

14. Holty JEC, Guilleminault C. Maxillomandibular advancement for the treatment of obstructive sleep apnea: A systematic review and meta-analysis. Sleep Med Rev. 2010;14(5):287-297. doi:10.1016/j.smrv.2009.11.003

15. Li KK, Powell NB, Riley RW, Troell RJ, Guilleminault C. Long-term results of maxillomandibular advancement surgery. Sleep Breath. 2000;4(3):137-139. doi:10.1007/s11325-000-0137-3

16. Ann H-R, Jung Y-S, Lee K-J, Baik H-S. Evaluation of stability after pre-orthodontic orthognathic surgery using cone-beam computed tomography: A comparison with conventional treatment. Korean J Orthod. 2016;46(5):301-309. doi:10.4041/kjod.2016.46.5.301

17. Sears CR, Miller AJ, Chang MK, Huang JC, Lee JS. Comparison of pharyngeal airway changes on plain radiography and cone-beam computed tomography after orthognathic surgery. J Oral Maxillofac Surg. 2011;69(11). doi:10.1016/j.joms.2011.03.015

18. Goncalves JR, Buschang PH, Goncalves DG, Wolford LM. Postsurgical Stability of Oropharyngeal Airway Changes Following Counter-Clockwise Maxillo-Mandibular Advancement Surgery. J Oral Maxillofac Surg. 2006;64(5):755-762. doi:10.1016/j.joms.2005.11.046

19. Gonçalves JR, Gomes LCR, Vianna AP, Rodrigues DB, Gonçalves DAG, Wolford LM. Airway space changes after maxillomandibular counterclockwise rotation and mandibular advancement with TMJ Concepts®total joint prostheses: Three-dimensional assessment. Int J Oral Maxillofac Surg. 2013;42(8):1014-1022. doi:10.1016/j.ijom.2013.04.009

20. De Souza Carvalho ACG, Magro Filho O, Garcia IR, Araujo PM, Nogueira RLM. Cephalometric and three-dimensional assessment of superior posterior airway space after maxillomandibular advancement. Int J Oral Maxillofac Surg. 2012;41(9):1102-1111. doi:10.1016/j.ijom.2012.05.009

21. Tiner BD. Maxillomandibular advancement surgery in obstructive sleep apnea syndrome patients: Long-term surgical stability. J Oral Maxillofac Surg. 1995;53(12):1418-1419. doi:10.1016/0278-2391(95)90668-1

22. Vyas D. Volumetric, planar and linear airway comparison after maxillomandibular advancement surgery. ProQuest Diss Theses. 2014.

23. Strauss RA, Wang N. Cone beam computed tomography and obstructive sleep apnoea. Aust Dent J. 2012;57:61-71. doi:10.1111/j.1834-7819.2011.01664.x

24. dos Reis Zinsly S, de Moraes LC, de Moura P, Ursi W. Assessment of pharyngeal airway space using Cone-Beam Computed Tomography. Dental Press J Orthod. 2010;15(5):150158. doi:10.1590/S2176-94512010000500018

25. OSA. https://www.mayoclinic.org/diseases-conditions/obstructive-sleep-apnea/symptoms- 
causes/syc-20352090.

26. Buchanan A, Cohen R, Looney S, Kalathingal S, De Rossi S. Cone-beam CT analysis of patients with obstructive sleep apnea compared to normal controls. Imaging Sci Dent. 2016;46(1):9-16. doi:10.5624/isd.2016.46.1.9

27. Rojo-Sanchis C, Almerich-Silla JM, Paredes-Gallardo V, Montiel-Company JM, BellotArcís C. Impact of Bimaxillary Advancement Surgery on the Upper Airway and on Obstructive Sleep Apnea Syndrome: A Meta-Analysis. Sci Rep. 2018;8(1):1-8. doi:10.1038/s41598-018-24142-3

28. Schendel S, Powell N, Jacobson R. Maxillary, mandibular, and chin advancement: Treatment planning based on airway anatomy in obstructive sleep apnea. J Oral Maxillofac Surg. 2011;69(3):663-676. doi:10.1016/j.joms.2010.11.010

29. El AS, El H, Palomo JM, Baur DA. A 3-dimensional airway analysis of an obstructive sleep apnea surgical correction with cone beam computed tomography. J Oral Maxillofac Surg. 2011;69(9):2424-2436. doi:10.1016/j.joms.2010.11.046

30. Giarda M, Brucoli M, Arcuri F, Benech R, Braghiroli A, Benech A. Efficacy and safety of maxillomandibular advancement in treatment of obstructive sleep apnoea syndrome. Acta Otorhinolaryngol Ital. 2013;33(1):43.

/pmc/articles/PMC3631807/?report=abstract\%5Cnpapers2://publication/uuid/34576865341B-4727-B3C3-3F419C955930.

31. CPAP. https://www.summitmedicalgroup.com/library/adult_health/aha_cpap/.

32. Doff MHJ, Jansma J, Schepers RH, Hoekema A. Maxillomandibular advancement surgery as alternative to continuous positive airway pressure in morbidly severe obstructive sleep apnea: A case report. Cranio - J Craniomandib Pract. 2013;31(4):246-251. doi:10.1179/crn.2013.31.4.001

33. mAD. https://www.sleep-apnea-guide.com/mandibular-advancement-device.html.

34. Riley RW, Powell NB, Li KK, Troell RJ, Guilleminault C. Surgery and obstructive sleep apnea: Long-term clinical outcomes. Otolaryngol Neck Surg. 2000;122(3):415-420. doi: $10.1067 / \mathrm{mhn} .2000 .102117$

35. Conradt R, Hochban W, Brandenburg U, Heitmann J, Peter JH. Long-term follow-up after surgical treatment of obstructive sleep apnoea by maxillomandibular advancement. Eur Respir J. 1997;10(1):123-128. doi:10.1183/09031936.97.10010123

36. Hayes MCJ, Dc U, Michaelson MPG, Mc U. A Review of the Surgical Treatment Options for the Obstructive Sleep Apnea / Hypopnea Syndrome Patient. 2014;175(September 2010):676-685. doi:10.1016/j.ajem.2015.10.018

37. mMA. https://www.sciencedirect.com/topics/medicine-and-dentistry/maxillomandibularadvancement.

38. McNamara JA. A method of cephalometric evaluation. Am J Orthod. 1984;86(6):449-469. doi:10.1016/S0002-9416(84)90352-X 
39. McKnamara.

http://www.jorthodr.org/viewimage.asp?img=JOrthodRes_2015_3_2_108_149051_f1.jpg.

40. Raffaini M, Pisani C. Clinical and cone-beam computed tomography evaluation of the three-dimensional increase in pharyngeal airway space following maxillo-mandibular rotation-advancement for Class II-correction in patients without sleep apnoea (OSA). $J$ Cranio-Maxillofacial Surg. 2013;41(7):552-557. doi:10.1016/j.jcms.2012.11.022

41. Lee SH, Kaban LB, Lahey ET. Skeletal stability of patients undergoing maxillomandibular advancement for treatment of obstructive sleep apnea. J Oral Maxillofac Surg. 2015;73(4):694-700. doi:10.1016/j.joms.2014.10.018

42. McCrillis JM, Haskell J, Haskell BS, et al. Obstructive Sleep Apnea and the Use of Cone Beam Computed Tomography in Airway Imaging: A Review. Semin Orthod. 2009;15(1):63-69. doi:10.1053/j.sodo.2008.09.008

43. CBCT. https://en.wikipedia.org/wiki/Cone_beam_computed_tomography.

44. Gribel BF, Gribel MN, Frazão DC, McNamara JA, Manzi FR. Accuracy and reliability of craniometric measurements on lateral cephalometry and 3D measurements on CBCT scans. Angle Orthod. 2011;81(1):28-37. doi:10.2319/032210-166.1

45. Patcas R, Müller L, Ullrich O, Peltomäki T. Accuracy of cone-beam computed tomography at different resolutions assessed on the bony covering of the mandibular anterior teeth. Am J Orthod Dentofac Orthop. 2012;141(1):41-50.

doi:10.1016/j.ajodo.2011.06.034

46. Martins LS, Liedke GS, Heraldo LD da S, et al. Airway volume analysis: is there a correlation between two and three-dimensions? Eur J Orthod. 2018;40(3):262-267. doi:10.1093/ejo/cjx067

47. Machado GL. CBCT imaging - A boon to orthodontics. Saudi Dent J. 2015;27(1):12-21. doi:10.1016/j.sdentj.2014.08.004

48. Bazina M, Cevidanes L, Ruellas A, et al. Precision and reliability of Dolphin 3dimensional voxel-based superimposition. Am J Orthod Dentofac Orthop. 2018;153(4):599-606. doi:10.1016/j.ajodo.2017.07.025

49. El H, Palomo JM. Measuring the airway in 3 dimensions: A reliability and accuracy study. Am J Orthod Dentofac Orthop. 2010;137(4 SUPPL.):S50.e1-S50.e9. doi:10.1016/j.ajodo.2009.11.010

50. Ghoneima A, Cho H, Farouk K, Kula K. Accuracy and reliability of landmark-based, surface-based and voxel-based 3D cone-beam computed tomography superimposition methods. Orthod Craniofacial Res. 2017;20(4):227-236. doi:10.1111/ocr.12205

51. Schendel SA, Broujerdi JA, Jacobson RL. Three-dimensional upper-airway changes with maxillomandibular advancement for obstructive sleep apnea treatment. Am J Orthod Dentofac Orthop. 2014;146(3):385-393. doi:10.1016/j.ajodo.2014.01.026

52. Kochar GD, Sharma M, Kumar S, et al. Pharyngeal airway evaluation following isolated surgical mandibular advancement: A 1-year follow-up. Am J Orthod Dentofac Orthop. 
2019;155(2):207-215. doi:10.1016/j.ajodo.2018.03.023

53. Torres HM, Valladares-Neto J, Torres ÉM, Freitas RZ, Silva MAG. Effect of Genioplasty on the Pharyngeal Airway Space Following Maxillomandibular Advancement Surgery. $J$ Oral Maxillofac Surg. 2017;75(1):189.e1-189.e12. doi:10.1016/j.joms.2016.09.005

54. Proffit WR, Turvey TA, Phillips C. The hierarchy of stability and predictability in orthognathic surgery with rigid fixation: an update and extension. Head Face Med. 2007;3(1):21. doi:10.1186/1746-160X-3-21

55. Ferraz O, Guimarães TM, Rossi RR, et al. Effectiveness of Maxillomandibular advancement (MMA) surgery in sleep apnea treatment: Case report. Sleep Sci. 2016;9(3):134-139. doi:10.1016/j.slsci.2016.07.005

56. Talebzadeh N, Pogrel MA. Long-term hard and soft tissue relapse rate after genioplasty. Oral Surg Oral Med Oral Pathol Oral Radiol Endod. 2001;91(2):153-156. doi:10.1067/moe.2001.112392

57. Butterfield KJ, Marks PLG, McLean L, Newton J. Linear and volumetric airway changes after maxillomandibular advancement for obstructive sleep apnea. J Oral Maxillofac Surg. 2015;73(6):1133-1142. doi:10.1016/j.joms.2014.11.020

58. Riley RW, Powell NB, Li KK, Troell RJ, Guilleminault C. Surgery and Obstructive Sleep Apnea: Long-Term Clinical Outcomes. Otolaryngol Neck Surg. 2000;122(3):415-421. doi:10.1016/S0194-5998(00)70058-1

59. Susarla SM, Abramson ZR, Dodson TB, Kaban LB. Upper airway length decreases after maxillomandibular advancement in patients with obstructive sleep apnea. $J$ Oral Maxillofac Surg. 2011;69(11):2872-2878. doi:10.1016/j.joms.2011.01.005 


\section{Appendix}

Appendix A

Acknowledgement Letter Not Human Subject Research NHSR
Office of Rescurch Integrity and Compliance
Action Date
$\begin{array}{ll}\text { To } & 05 / 08 / 2017 \\ \text { From } & \text { Peter Ngan } \\ \text { Approval Date } & \text { WVU Office of Research Integrity and Compliance } \\ \text { Expiration Date } & 05 / 08 / 2017 \\ \text { Subject } & 05 / 07 / 2022 \\ \text { Protocol Number } & \text { Not Human Subject Research Acknowledgment } \\ \text { Title } & \text { 1704532922 } \\ & \text { Airway Changes and Stability after Maxillomandibular Advancement Surgery: A } \\ \text { three-dimensional retrospective study }\end{array}$

Thank you for your submission to the West Virginia University Institutional Review Board IRB.

It has been deteminined that your project does not meet the definition of human subject research for the following reasons:

Documents reviewed and/or approved as part of this submission:

Proposal.docx: 2017-04-04-04:00

permission letter.pdf: 2017-04-04-04:00

The Office of Research Integrity and Compliance is here toprovide assistance to you from the initial submission of an IRB protocol to its approval and all subsequent activity. Please feel free to contact us by phone at 304.293.7073 with any question you may have. Thank you.

WVU Office of Research Integrity and Compliance

Date:05/08/2017

Signed:

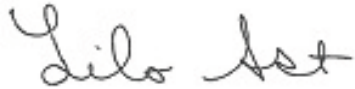

Lilo Ast 
Appendix B

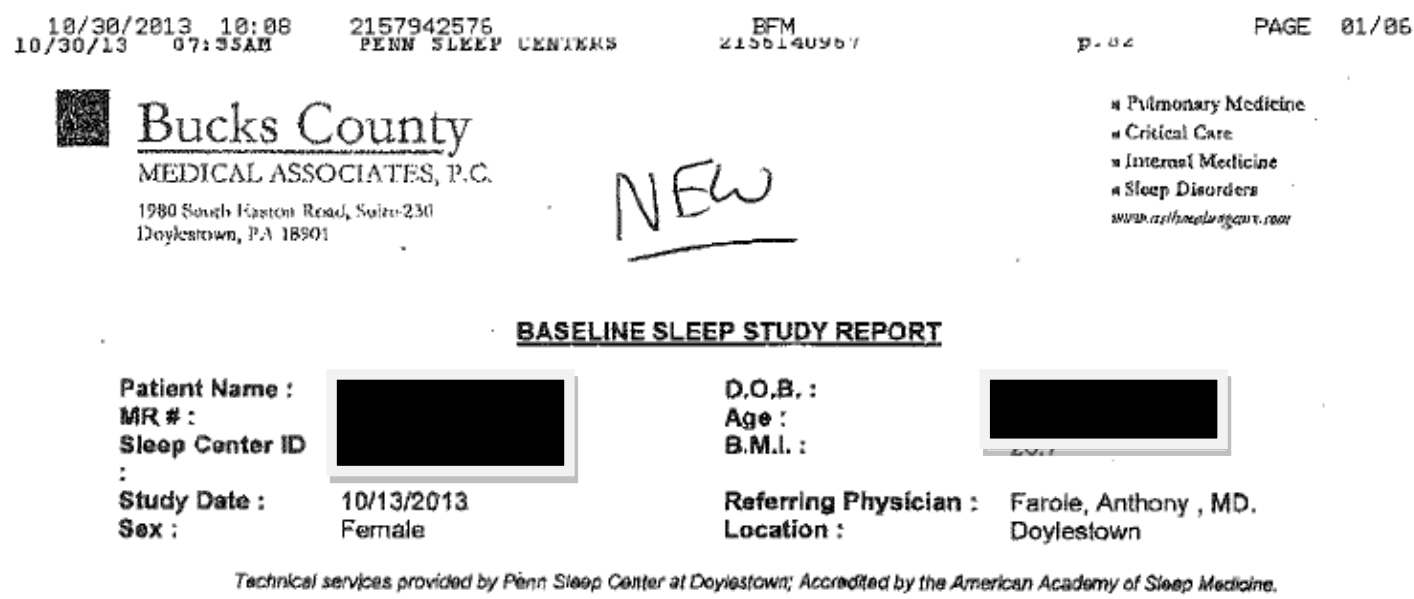

CLINICAL. HISTORY: The pationt is a 41 years old woman with a history of hypertension who complains of encring, witneseed apneas, surgery for sleep apnea, CPAP' fallure, and excessive daytime sleepiness (Epworth Sleepiness Score $=12$ ). A sleep study was arranged to evaluate the patient for obstructive sloop apnea syndrome.

TECHNICAL DESCRIPTION: The patient underwent full overnight polysomnography during which the following parameters were monitored; EEG (C3-M2, C4-M1, F3-M2, F4-M1, O1-M2, O2-M1), EOG, submental and $\log$ EMG, ECG, oxyhemoglobin saturation by pulse oximetry, respiratory effort, nasaloral airflow, and snoring

SLEEP-DISORDERED BREATHING:

Total Apnea/Hypopnea index (AHI):

Supine AHI:

Lateral $A H !$

REM AHI:

NREM Oxyhemoglobin Desaturation Nadir:

REM Oxyhemogiobin Desaturation Nadir

11
33
4
0
89.0
89.0

FINDINGS: Sleep efficiency was $78.3 \%$ with a latency to sleep of 21.2 minutes. Distribution of sleep stages was as follows: $11.8 \%$ stage N1 sleep; $56.2 \%$ stage N2 sleep: $10.4 \%$ stage N3 sieep; $21.7 \%$ REM sleep. The REM Sleep latency was 137.0 minutes. There were 40.2 arousals per hour. There were 0.0 periodic limb movements. EKG demonstrated sinus rhythm.

Moderate snoring levels are shown on the accompanying printout. There were 0 central apneas, 3 obstructive apneas and 67 hypopneas producing an apnea/hypopnea index (AHI) of 10.8 events per hour in total, and REM-felated AHI of 0.0 events per hour. Oxyhemoglobin desaturation reached a nadir of B9.0 during non-REM sleep and 95.0 during REM sleep. Respiratory events were scored according to AASM criteria.

FINAL DIAGNOSIS:

1. Obstructive sleep apnea $(327.23)$

COMMENTS AND RECOMMENDATIONS: The patient has evidence for sleep disordered breathing especially in the supine position and in REM sleep. Treatment options include weight loss, positional therapy, CPAP therapy, upper airway surgery, or the use of an oral appliance. I will set her up with a CPAP titration study or autoPAP if she is willing with follow up at the Sleep Center.

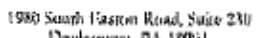

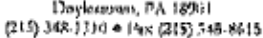

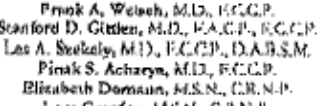

Elizabeth Domain, w.S. N. C.R.N.

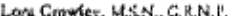

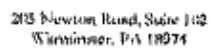

(215) 348.1316 


\title{
Appendix C
}

\author{
Mary E. Bums, DMD. \\ 120 Bridce Sheel Sulte \\ New Hope. Fennsylvania 18938 \\ Tolephone: (215) 862-2275
}

February 6, 2017

\section{To Whom This May Concern,}

Dear Sir/Madam,

This is to inform you that I will support the project "Airway Changes and Stability after Maxillomandibular Advancement Surgery: A three-dimensional retrospective study" conducted by Dr. Ghaddy Alsaty and Dr. Peter Ngan and I will grant permission for them to access my patient records.

I understand that all patients' records will be de-identifed and will be coded by numbers to protect patient confidentiality.

Thank you for your kind attention.

Sincerely,

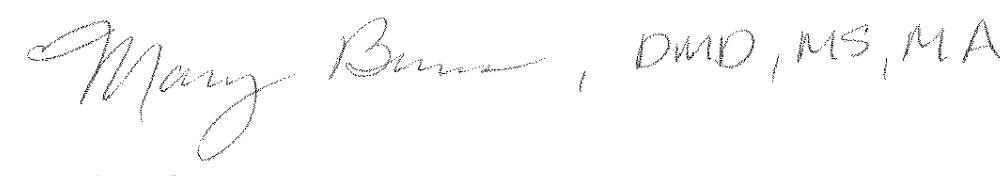

Dr. Mary Burns 